\title{
DYNAMIC LAFFER CURVES AND POPULATION GROWTH
}

\author{
by
}

\author{
Shumaila Waqas \\ Islamabad, 2000 \\ B.A, University of the Punjab, Islamabad, 1997 \\ A major research paper \\ presented to Ryerson University \\ in partial fulfillment of the \\ requirement for the degree of \\ Master of Arts \\ in the program of \\ International Economics and Finance
}

M.Sc Economics, International Islamic University, Islamabad, 2000

Diploma in Management/Teaching, National Institute of Science and Technical Education,

Toronto, Ontario, Canada, 2019

CShumaila Waqas, 2019 


\section{Author's Declaration}

I hereby declare that I am the sole author of this MRP. This is a true copy of the MRP including any required final revisions.

I authorize Ryerson University to lend this MRP to other institutions or individuals for the purpose of scholarly research.

I further authorize Ryerson University to reproduce this MRP by photocopying or by other means, in total or in part, at the request of other institutions or individuals for the purpose of scholarly research.

I understand that my MRP may be made electronically available to the public. 


\title{
CDYNAMIC LAFFER CURVES AND POPULATION GROWTH
}

\author{
Shumaila Waqas \\ Master of Arts 2019 \\ International Economics and Finance \\ Ryerson University
}

\begin{abstract}
This paper extends the model of Ireland (1994) by incorporating population growth in examining the dynamic effects of a tax cut on the government's intertemporal budget constraint. A tax cut has two opposing effects. First, it increases the growth rate of the economy and, thus, increases the size of the tax base and tax revenues in the future. On the other hand, a reduction in the tax rate leads to a decrease in revenues in the short run. A dynamic Laffer curve effect arises if a decrease in tax revenue can be counter-balanced by a future increase in tax revenue to ensure that the government's intertemporal budget constraint is not violated. Similarly, population growth has two opposing effects. A high population growth decreases the per capita growth rate of the economy. On the other hand, a larger population represents a larger tax base and, therefore, makes it easier for a government to finance a budget deficit. Relative to the simulation results in Ireland (1994), our simulations indicate that incorporating population growth into his model implies that the dynamic effect of a given tax cut worsens the government's long-run fiscal outlook.
\end{abstract}




\section{Acknowledgements}

I would like to express my sincere appreciation to my Supervisor, Dr. Constantine Angyridis for his constant guidance, encouragement and literature support, without which this work would not have been possible. For his unwavering support, I am truly grateful.

I am also grateful to all the instructors at Ryerson University, Department of Economics for their support towards the successful completion of my studies.

I also would like to express my heartfelt gratitude to Dr. Maurice. J. Roche, my program advisor who always encouraged me to finish my tasks.

I also would like to acknowledge Professor Cathy Ning for reading and suggesting revisions in my draft. I am very grateful for the time she has spent as it has allowed me to improve my paper.

I would like to extend my gratitude towards my husband and my children for their part in my journey. My thanks and my appreciation also goes to my parents, my beloved Siblings, my colleagues, my friends and my Supervisors at work who have given me time and strength to pursue my studies. 


\section{Dedication}

I dedicate this work to my Supervisor and a very Special teacher, Dr. Constantine Angyridis. I have learned a lot through his lectures, course material and his depth of knowledge. He is an inspiration for me to work to my best. I am very grateful for the time and the commitment he gave me throughout my research paper. I would not have been able to finish my task without his supreme guidance. In fact, all my work reflects his continuous guidance. I am truly honored to work with such an exemplary professor. 


\section{Table of Contents}

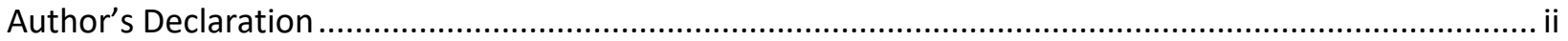

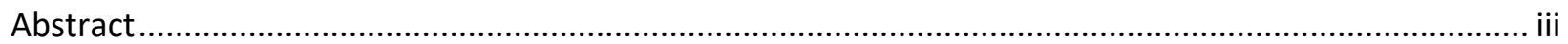

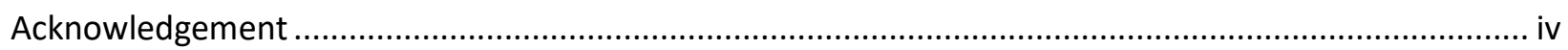

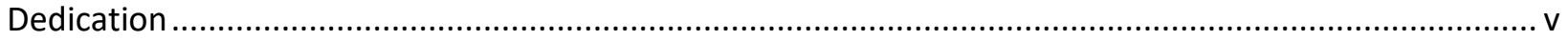

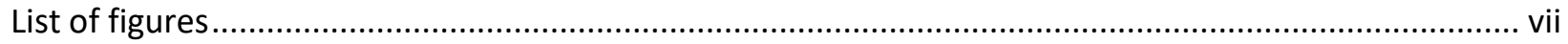

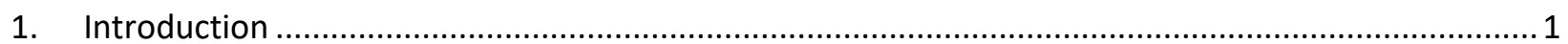

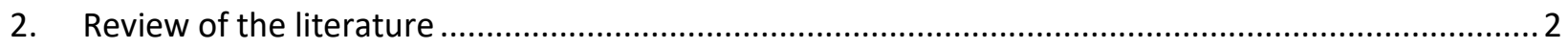

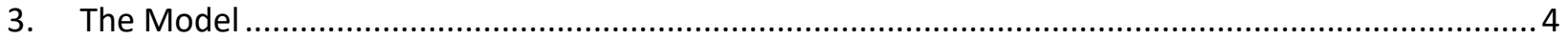

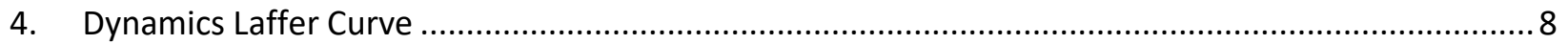

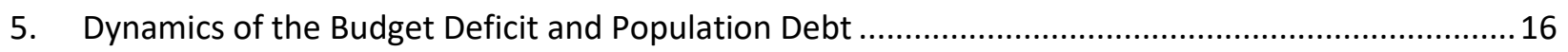

6. Dynamic Laffer Curve and Population Growth ….....................................................................

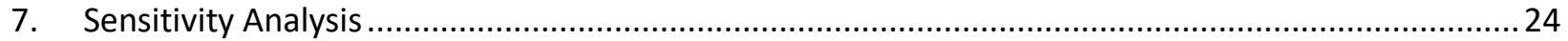

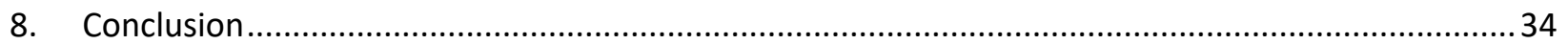

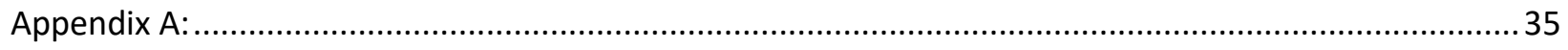

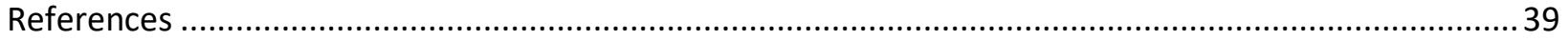




\section{List of figures}

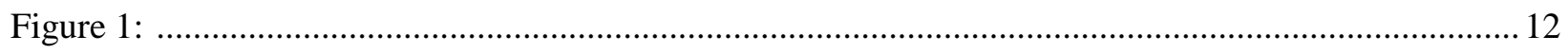

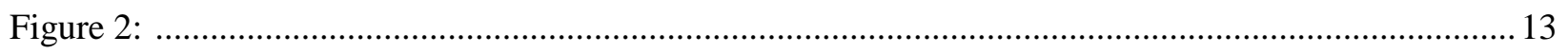

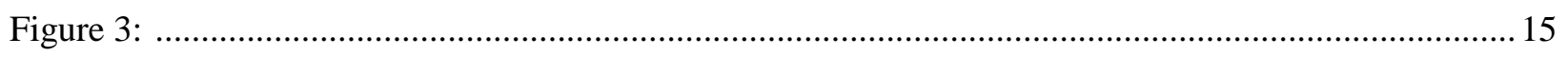

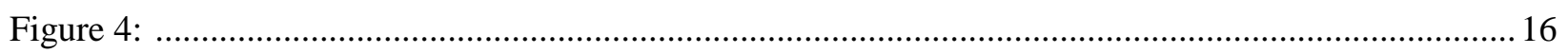

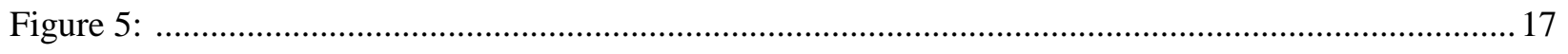

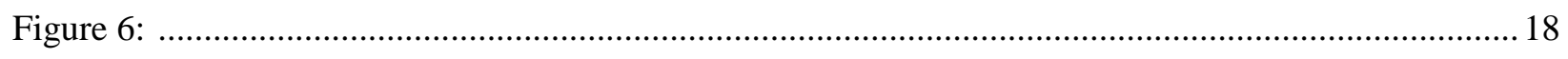

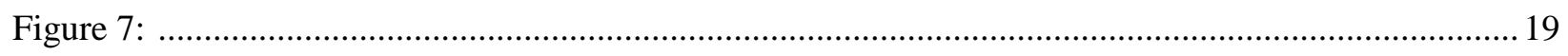

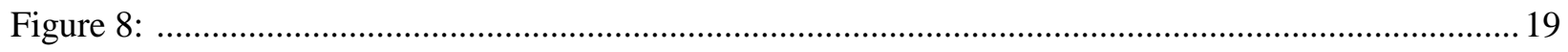

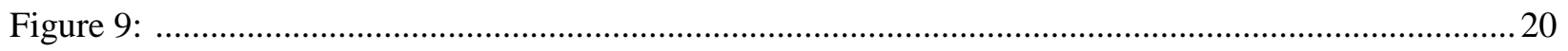

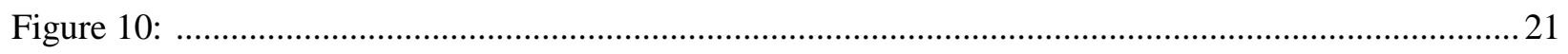

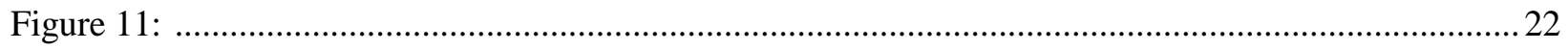

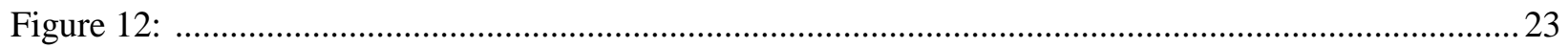

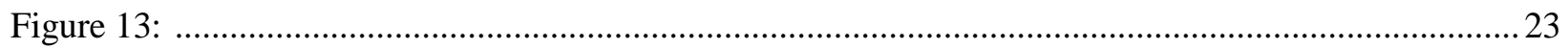

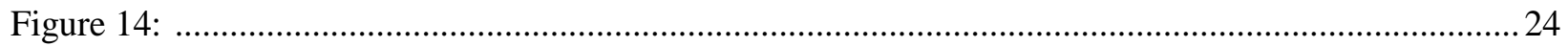

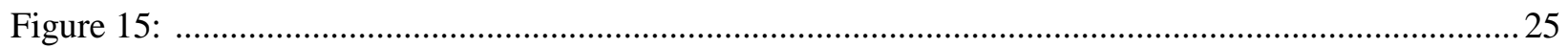

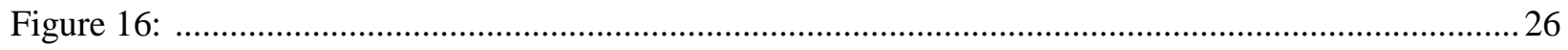

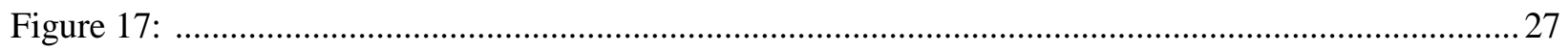

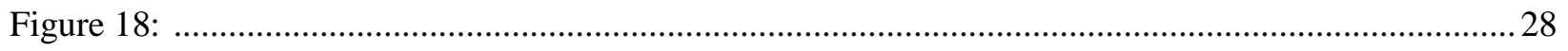

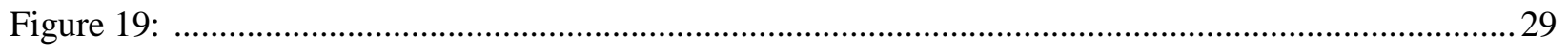

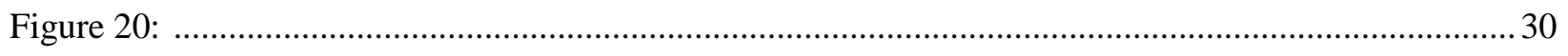

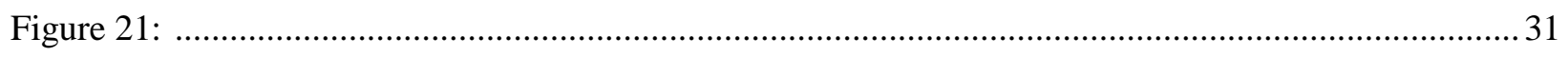

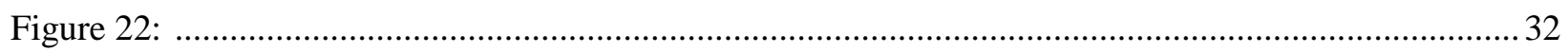

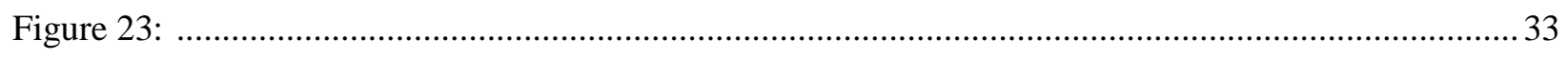

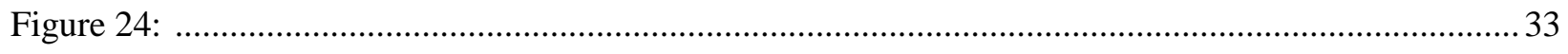




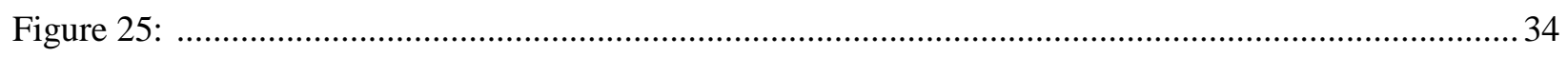




\section{Introduction}

One of the most controversial issues in tax policy analysis is whether tax cuts will stimulate economic activity to an extent where the government's long-run budget outlook will improve. Ireland (1994) develops an endogenous growth model and shows that there exists a dynamic Laffer curve. The real effects of a deficit-financed tax cut have many points in common with the standard Laffer curve analysis. If the economy is located on the positively sloped portion of the Laffer curve, a reduction in the tax rate causes tax revenues to decrease. Hence, for a given stream of government expenditures, budget deficits will tend to increase. In contrast, tax revenues will increase and the deficit will decrease if the economy is located on the negatively sloped portion of the Laffer curve. Following Ireland (1994), we examine the dynamic effect of a tax cut on the government's intertemporal budget constraint. Relative to his work, we incorporate population growth in the analysis. We show that higher population growth has negative effects on the government's intertemporal budget constraint.

Recent debates among economists and policymakers have focused on the growth-enhancing effects associated with the tax reductions. The debt crisis in Europe has reversed several tax cuts trends. These changes are partly attributable to policy debates on the dynamic effects of tax cuts on the government's intertemporal budget constraint. Although tax cuts are meant to stimulate an economy in both the short and long term, they may exacerbate problems associated with short-term debt and can contribute to long-term debt accumulation. Most advanced economies stagnate and carry a large amount of outstanding debt. Tax changes that avoid deteriorating the short-term debt situation while mitigating debt accumulation in the long-run would prove most effective. To explore the dynamic Laffer effects, we employ a simple endogenous growth model with population growth, in line with the work by Ireland (1994). 
The paper is organized as follows. Section 2 reviews the related literature. The model is described in Section 3. The Dynamic Laffer Curve is discussed in Section 4. Section 5 sheds light on the dynamics of the budget deficit and public debt. The relationship between the dynamic Laffer curve and population growth is analyzed in Section 6. There is sensitivity analysis in section 7.The paper concludes in Section 8 .

\section{Review of the literature}

Using a similar model to ours, Agell and Persson (2001) shed light on the dynamics of Laffer curve effects. Traditionally, the concept of a Laffer curve has been discussed in the context of static models. One of the controversial issues in tax policy analysis is whether tax cuts will stimulate economic activity to an extent where the government budget will improve. The authors use an $A K$ endogenous growth model and show that a dynamic Laffer curve effect is only possible for the high tax and high transfer economies of Northern and Western Europe. However, using a similar model, Bruce and Turnovsky (1999) conclude that dynamic Laffer effects will not occur in practice. According to these authors, a tax cut can only improve the long-run fiscal balance if the intertemporal elasticity of substitution is much above unity.

Dalamagus (1998) provided a simple framework in the context of an endogenous growth model. The main finding is that in the Group of Seven $(\mathrm{G} 7)$ the effects of tax rate changes cannot be unambiguously determined unless the crowding-out and crowding-in aspects of government intervention are considered. The government is "crowding out" because it is demanding more loanable funds which cause an increase in interest rates. On the other hand, the government is "crowding in" when budget deficits are used to spur investment. The primary objectives of the author were to examine whether: 
(i) There would have been a robust and systematic tendency for fiscal deficits to decline within each of the G7 industrial countries if tax rates had been set at lower levels.

(ii) If so, to investigate whether such a tendency can be explained by the differential impact of the tax burden on private-capital productivity and, hence, on the growth rate.

The estimates of the study suggest that the expansionary effects of lower taxes can generate smaller deficits in the long-run only for the USA, UK and Italy. Hence, alleviating the average tax burden in these countries would moderate the disincentive effects of taxation and would mitigate the impact of the public sector on the private sector's investment rate and output. In contrast, a permanent reduction in the average tax rates resulted in both low rates of real growth and increasing long-run government budget deficits in Japan, Germany and Canada, where public sector activity complements private capital in the production of private goods. The empirical evidence with respect to the seventh country, France, is inconclusive as long-run government budget deficits for this country never appeared to respond in either way to tax-rate changes.

Novales and Ruiz (2002) analyze the possible gains of substituting debt for taxes in deficit management. They show that a tax cut will generally have a positive impact on the growth rate of the economy. The authors also find that a reduction in the labor income tax produces a larger stimulus on long-run growth than a reduction in the capital income tax.

Strulik and Trimborn (2012) highlighted how capital taxation affects tax revenues in general equilibrium. A neoclassical growth model is extended to include a corporate sector, an investment and finance decision by firms, and a set of taxes on capital income. These authors also provide analytical dynamic scoring of taxes on corporate income, dividends, and capital 
gains, other private capital income and depreciation allowances. They also identify the ways through which capital taxation affects tax revenue in general equilibrium. Generally, some capital taxes are more distortionary than others. For instance, the authors' analysis suggests that corporate taxes can be drastically reduced with little effect on tax revenues and that the revenuemaximizing tax rate on capital gains is zero.

Trabandt and Uhlig (2011) show that there is a Laffer curve in standard neoclassical growth models with respect to both capital and labor income taxation. The authors also find that lowering the capital income tax and raising the labor income tax leads to higher tax revenues in both the US and EU-14 countries. They also determine that the Laffer curve for consumption taxes does not have a peak and is increasing in the consumption tax rate. Finally, Trabandt and Uhlig (2011) find that although both the US and the EU-14 countries are located on the left side of their respective Laffer curves, the US can increase tax revenues by $30 \%$ by raising labor taxes while the EU-14 countries can raise only an additional 8\%.

\section{The Model}

Consider a closed economy in discrete time as in Ireland (1994). Output $Y_{t}$ is produced by using capital $K_{t}$ according to the production function:

$$
Y_{t}=A K_{t}, \quad A>0
$$

King and Rebelo (1990) and Rebelo (1991) demonstrate that this simple linear model captures both qualitatively and quantitatively nearly all of the long-run policy implications of more general models of endogenous growth in which the accumulation of multiple capital goods is

considered explicitly. The initial capital stock is $K_{0}=1$ and the tax rate is constant at $\tau^{0}$ for all $t$. The population is denoted as $N_{t}$ and is assumed to grow at a constant rate $n$. This latter feature 
distinguishes our framework with that of Ireland (1994). The aggregate capital stock depreciates at rate $\delta$ and it grows through private investment $I_{t}$ in each period $t$. Hence,

$$
K_{t+1}=(1-\delta) K_{t}+I_{t}
$$

At each date $t$, the government levies a proportional income tax $\tau_{t}$ and provides consumers with a lump sum transfer $G_{t}$. The government finances a deficit by issuing oneperiod bonds. The real interest rate in period $t$ is defined as $R_{t}$. The government sells $B_{t+1} / R_{t}$ in period $t$ and pays off $B_{t+1}$ in period $t+1$. The consumer's budget constraint is given by

$C_{t}+I_{t}+\frac{B_{t+1}}{R_{t}} \leq\left(1-\tau_{t}\right) Y_{t}+B_{t}+G_{t}$

Substituting for investment, the above expression becomes

$C_{t}+K_{t+1}+\frac{B_{t+1}}{R_{t}} \leq\left(1-\tau_{t}\right) Y_{t}+(1-\delta) K_{t}+B_{t}+G_{t}$

Given that the size of the population is equal to $N_{t}$, the aggregate production function can be written in per capita terms as

$\frac{Y_{t}}{N_{t}}=A\left(\frac{K_{t}}{N_{t}}\right)$

or, equivalently

$y_{t}=A k_{t}$

where $y_{t}=Y_{t} / N_{t}$ and $k_{t}=K_{t} / N_{t}$. Recall that the population is assumed to grow at a constant rate:

$N_{t+1}=(1+n) N_{t}$

It follows that the private sector's budget constraint can be expressed in per capita terms as:

$c_{t}+(1+n) k_{t+1}+(1+n) \frac{b_{t+1}}{R_{t}} \leq\left(1-\tau_{t}\right) y_{t}+(1-\delta) k_{t}+b_{t}+g_{t}$, 
where $c_{t}=C_{t} / N_{t}, b_{t}=B_{t} / N_{t}$ and $g_{t}=G_{t} / N_{t}$.

The infinitely-lived representative agent in this economy seeks to maximize lifetime utility. Assuming that the utility function is constant-relative-risk-aversion (CRRA), the agent's objective function is:

$$
U=\sum_{t=0}^{\infty} \beta^{t}\left[\frac{c_{t}^{1-\sigma}-1}{1-\sigma}\right], \quad \beta \epsilon(0,1) ; \sigma>0
$$

The representative agent's intertemporal optimization problem involves maximizing (3) subject to (1) and (2). The Lagrangian for this problem is

$$
\begin{gathered}
\mathcal{L}=\sum_{t=0}^{\infty} \beta^{t}\left[\frac{c_{t}^{1-\sigma}-1}{1-\sigma}\right]+\lambda_{t}\left[\left(1-\tau_{t}\right) A k_{t}+(1-\delta) k_{t}+b_{t}+g_{t}-c_{t}-(1+n) k_{t+1}\right. \\
\left.-(1+n)\left\{\left(b_{t+1}\right) / R_{t}\right\}\right] .
\end{gathered}
$$

As it is shown in Appendix A.1, the Euler equation for this problem is

$\frac{c_{t+1}}{c_{t}}=\left[\frac{\beta R_{t}}{1+n}\right]^{\frac{1}{\sigma}}$

where

$R_{t}=\left(1-\tau_{t+1}\right) A+(1-\delta)$.

Letting $\gamma_{t}$ denote the growth rate of consumption, it follows from (4) that

$\gamma_{t}=\left[\frac{\beta R_{t}}{1+n}\right]^{\frac{1}{\sigma}}$.

Expression (5) shows that the economy's growth rate is inversely related to the tax rate through $R_{t}$. If the tax rate is constant over time, then consumption, output and capital will all grow at a constant rate. 
As it is shown in Appendix A.2, the following transversality condition needs to be satisfied:

$\lim _{t \rightarrow \infty}(1+n)^{t+1}\left[\frac{\left\{k_{t+1}+b_{t+1} / R_{t}\right\}}{\Pi_{s=0}^{t-1} R_{s}}\right]=0$.

This condition guarantees that the period-by-period budget constraints (2) can be combined into a single present value budget constraint. The representative agent takes the initial capital stock and public debt, as well as the sequences of taxes, transfers and after-tax interest rates as given when maximizing lifetime utility.

It is assumed that the government has committed itself to providing a sequence $\left\{G_{t}\right\}_{t=o}^{\infty}$ of transfers to consumers. The transfers are financed either through taxation or by issuing bonds. The government budget constraint is given as

$\frac{B_{t+1}}{R_{t}}+\tau_{t} Y_{t} \geq B_{t}+G_{t}$

The above constraint can be expressed in per capita terms as

$\tau_{t} A k_{t}+(1+n) \frac{b_{t+1}}{R_{t}} \geq b_{t}+g_{t}$

Similar to (6), the transversality condition for the government is

$\lim _{\mathrm{t} \rightarrow \infty}(1+n)^{t+1}\left[\frac{\mathrm{b}_{\mathrm{t}+1} / \mathrm{R}_{\mathrm{t}}}{\prod_{s=0}^{t-1} R_{s}}\right]=0$.

Terminal condition (8) ensures that the period-by-period constraints (7) can be combined into a single intertemporal budget constraint. The government takes the initial conditions $k_{0}>0$ and $b_{0} \geq 0$, as well the sequences $\left\{k_{t+1}\right\}_{t=0}^{\infty}$ and $\left\{R_{t}\right\}_{t=0}^{\infty}$ as given.

Combining (2) and (7) yields the economy's resource constraint in per capita terms:

$$
c_{t}+(1+n) k_{t+1}+(1+n) \frac{b_{t+1}}{R_{t}} \leq A k_{t}+(1-\delta) k_{t}+b_{t}+g_{t}
$$


The equilibrium path of the economy is a balanced growth path (BGP). Along the BGP, $\left\{c_{t}, y_{t}, g_{t}, k_{t+1}, b_{t+1}\right\}$ all grow at the same rate $\gamma_{t}$. The tax rate is assumed to be constant. Hence, assuming that $\tau_{t}=\tau$, it follows from (4) and (5) that

$$
\gamma=\left[\frac{\beta\{(1-\tau) A+(1-\delta)\}}{1+n}\right]^{\frac{1}{\sigma}} .
$$

\section{Dynamic Laffer Curve}

Consider the special case of the economy where the initial capital stock is given as $k_{0}=1$ and the tax rate is equal to $\tau^{0}$ for all $t$. The initial debt is $b_{0} \geq 0$. Let

$R^{0}=\left(1-\tau^{0}\right) A+(1-\delta)$.

From (5) it follows that

$\gamma^{0}=\left[\frac{\beta R^{0}}{1+n}\right]^{\frac{1}{\sigma}}$.

Following Ireland (1994), we initially assume that the government balances its budget period-by-period. Expression (7) implies then that transfers evolve over time as

$g_{t}^{0}=\left(\gamma^{0}\right)^{t} \theta$,

where

$\theta=\tau^{0} A+b_{0}\left[\frac{\gamma^{0}(1+n)}{R^{0}}-1\right]$

As in Ireland (1994), we pose the following question: is there a lower tax rate $\tau^{1}<\tau^{0}$ that can finance the same sequence of lump-sum transfers $\left\{g_{t}^{0}\right\}_{t=0}^{\infty}$ as the one given above? If such a new tax rate exists, then there is a "dynamic Laffer curve effect". The sequence of lump-sum transfers is likely financed through short-run deficits, while in the long-run the government balances its budget. 
With $\tau_{t}=\tau^{1}<\tau^{0}$ for all $t$, the after-tax real interest rate is given by

$R^{1}=\left(1-\tau^{1}\right) A+(1-\delta)$,

while the growth of the economy is

$\gamma^{1}=\left[\frac{\beta R^{1}}{1+n}\right]^{\frac{1}{\sigma}}$

Given that $k_{0}=1$, using (10a) and (10b), it follows that

$$
k_{t}^{1}=\left[\frac{\beta\left[\left(1-\tau^{1}\right) A+(1-\delta)\right]}{1+n}\right]^{\frac{t}{\sigma}}
$$

Equation (11) describes the evolution of the capital stock per capita over time after the tax cut. The government's present value budget constraint is obtained by using repeated forward substitutions of (7) and imposing transversality condition (8):

$\sum_{t=0}^{\infty}(1+n)^{t}\left[\Pi_{s=0}^{t-1} R_{s}\right]^{-1}\left[\tau^{1} A k_{t}^{1}-g_{t}^{0}\right] \geq b_{0}$

Substituting $k_{t}^{1}$ and $R^{1}$ after the tax cut and $g_{t}^{0}$ before the tax cut into (12) implies that the government's present value budget constraint will be satisfied under the lower tax rate $\tau^{1}$ only if

$$
\sum_{t=0}^{\infty}\left(\frac{1+n}{R^{1}}\right)^{t} \tau^{1} A\left[\frac{\beta R^{1}}{1+n}\right]^{\frac{t}{\sigma}}-\sum_{t=o}^{\infty}\left(\frac{1+n}{R^{1}}\right)^{t}\left[\frac{\beta R^{0}}{1+n}\right]^{\frac{t}{\sigma}} \theta \geq b_{0}
$$

The reduction in the marginal tax rate from $\tau^{0}$ to $\tau^{1}$ has three effects on the government's budget constraint. First, the direct effect of the lower tax rate is that it decreases tax revenues. Second, the lower tax rate increases the rate of capital accumulation as shown in equation (11); this effect increases the size of the tax base and, hence, increases tax revenues. These two effects are captured by the first term in equation (13). Third, the lower tax rate increases the real rate of interest as shown in equation (11) and thereby decreases the present value of the government's future receipts and expenditures. This effect is captured by the denominator in (13). 
Expanding the first summation in (13) yields:

$\sum_{t=0}^{\infty}\left(\frac{1+n}{R^{1}}\right)^{t} \tau^{1} A\left[\frac{\beta R^{1}}{1+n}\right]^{\frac{t}{\sigma}}=\frac{\tau^{1} A R^{1}}{R^{1}-(1+n) \gamma^{1}}$

Furthermore, expanding the second summation in (13) we obtain:

$$
\sum_{t=0}^{\infty}\left(\frac{1+n}{R^{1}}\right)^{t}\left[\frac{\beta R^{0}}{1+n}\right]^{\frac{t}{\sigma}} \theta=\frac{\theta R^{1}}{R^{1}-(1+n) \gamma^{0}}
$$

Substituting the above two expressions back into (13) and rearranging yields equation (14) below that measures the total effect of the tax cut on the government's intertemporal budget constraint:

$$
L\left(\tau^{1}, \tau^{0}, A, \beta, \delta, \sigma, n, b_{0}\right)=\frac{\tau^{1} A}{\left[R^{1}-(1+n) \gamma^{1}\right]}-\frac{\tau^{0} A}{\left[R^{1}-(1+n) \gamma^{0}\right]}-w b_{0}
$$

where

$w=\frac{\left(R^{1}-R^{0}\right)(1+n) \gamma^{0}}{R^{0} R^{1}\left[R^{1}-(1+n) \gamma^{0}\right]}$

Function $L$ is generally monotonic in $\delta, \sigma$ and $b_{0}$ only, so it is not possible to determine analytically the range of parameter values for which $L \geq 0$. The value of function $L$ implies the presence of a dynamic Laffer curve. It is possible, however, to evaluate $L$ numerically when specific values are chosen for the parameters and see how the function changes as one of its arguments varies while the others are held constant.

Following King and Rebelo (1990), a set of parameters is chosen so that with $\sigma=1$, $\delta=0.1$, and $\tau^{0}=0.20$, the model economy's after-tax real rate of interest $R$ is $3.2 \%$ and its growth rate $\gamma$ is $2 \%$ per period. With a period in the model identified as a year, these numbers represent the after-tax real interest rates and the growth rates observed in the postwar U.S. economy. To match these two statistics, we set $A=0.165$ and $\beta=(1.02 / 1.032)$. Using these 
parameter values, we assess the feasibility of a permanent tax cut from $20 \%$ to $15 \%$. In performing this experiment, our objective is to replicate the numerical simulation results in Ireland (1994).

Each of Figures 1-4 below starts with the following parameter values:

$$
\begin{gathered}
\tau^{1}=0.15, \tau^{0}=0.20, A=0.165, n=0 \\
\beta=(1.02 / 1.032), \quad \delta=0.1, \sigma=1 .
\end{gathered}
$$

The real after-tax interest rate for the initial tax rate is calculated as follows:

$R^{0}=\left(1-\tau^{0}\right) A+(1-\delta)=(1-0.20) 0.165+(1-0.10)=1.032$

In addition, given that $\beta=0.988$ and $\sigma=1$, the economy's growth rate $\gamma^{0}$ under the constant rates $\tau^{0}$ is

$\gamma^{0}=\left(\beta R^{0}\right)^{\frac{1}{\sigma}}=(0.988 * 1.032)^{\frac{1}{1}}=1.02$.

Similarly, the new after-tax real interest rate after the tax cut is given by

$R^{1}=\left(1-\tau^{1}\right) A+(1-\delta)=(1-0.15) 0.165+(1-0.10)=1.0403$,

while the growth rate is

$\gamma^{1}=\left(\beta R^{1}\right)^{\frac{1}{\sigma}}=(0.988 * 1.0403)^{\frac{1}{1}}=1.0282$.

The value of the population growth rate is set equal to zero in order to replicate the results reported in Ireland (1994). The total effect of the tax cut on the government's budget is measured by equation (14). Following Ireland (1994), we refer to this calculation as the "budget effect". For the benchmark parameterization, we obtain

$$
\begin{aligned}
L\left(\tau^{1}, \tau^{0}, A, \beta, \delta, \sigma, n, b_{0}\right) & =\frac{\tau^{1} A}{R^{1}-\beta R^{1}}-\frac{\tau^{0} A}{R^{1}-\beta R^{0}} \\
& =\frac{0.15 * 0.165}{1.0403-0.988 * 1.0403}-\frac{0.20 * 0.165}{1.0403-0.988 * 1.032}=0.412 .
\end{aligned}
$$


A positive value for $L$ means that the supply-side policy experiment is feasible in the sense that the government's intertemporal budget constraint is not violated under the given set of parameter values.

Figure 1 below plots the budget effect for alternative values of $\tau^{1}$ keeping all other parameter values fixed. It shows that the budget effect $L$ is positive for all new tax rates $\tau^{1}$ greater than 0.076 . Thus, the tax rate can be reduced from its calibrated value of $20 \%$ to any rate greater than $7.6 \%$ while still balancing the government's present value budget constraint in the long run.

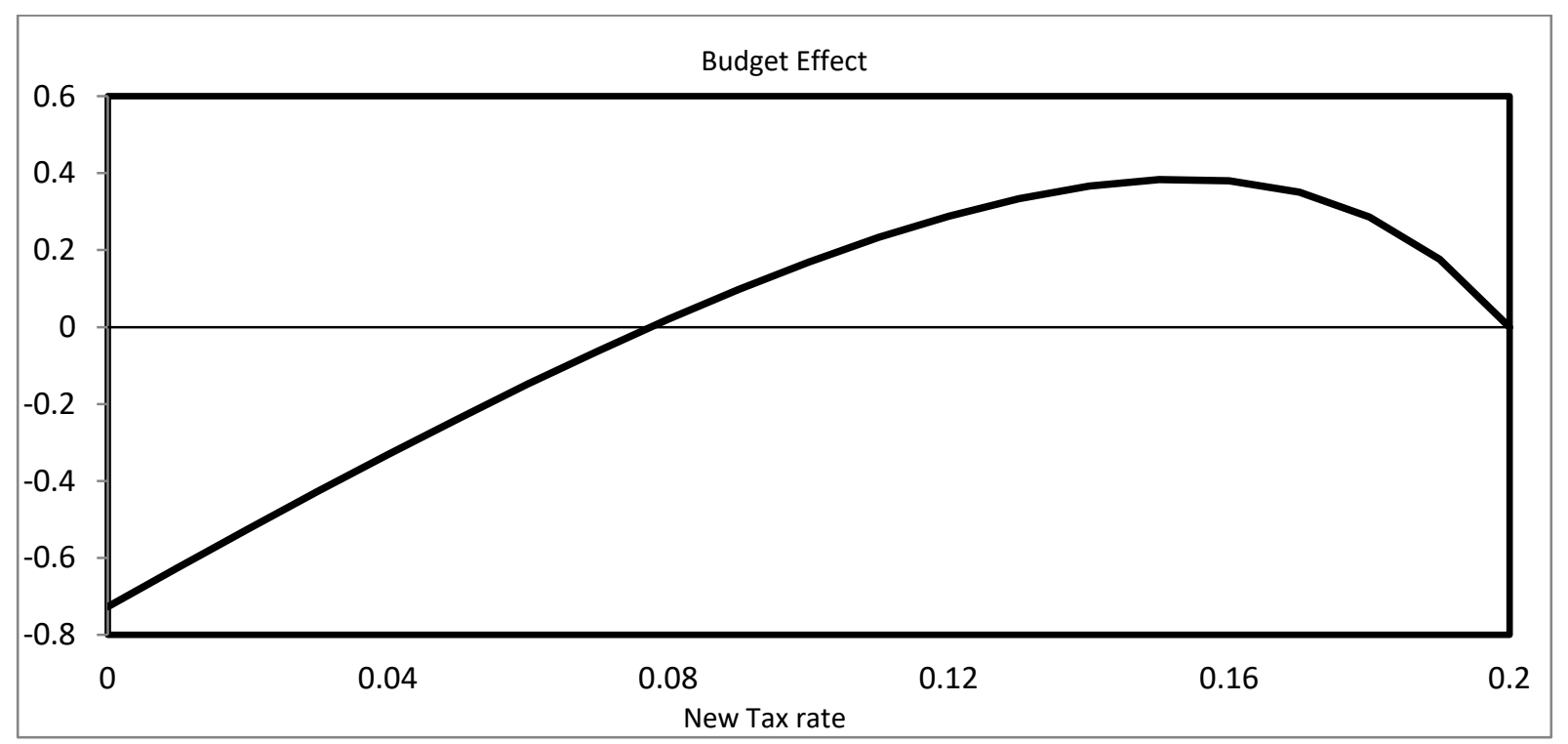

Fig.1. The budget effect in relation to the new tax rate $\tau^{1}$.

The budget effect $L$ is given by eq.(14); a positive value for $L$ indicates that the government's budget constraint is satisfied and the tax cut from $\tau^{0}$ to $\tau^{1}$ is feasible.

In addition to its effect on the government's intertemporal budget constraint, a tax cut causes the economy's growth rate to change. Following Ireland (1994), we will refer to this as 
the "growth effect" of the tax cut. Using the parameterization outlined above, we calculate the growth effect as

Growth Effect $=100 \times\left(\gamma^{1}-\gamma^{0}\right)=100 \times(1.0282-1.02)=0.78$.

Figure 2 below depicts the growth effect for alternative values of $\tau^{1}$ keeping all other parameter values fixed. It shows that the economy's growth rate increases by roughly $0.8 \%$ when $\tau^{1}=0.15$. In other words, a reduction in the tax rate from $20 \%$ to $15 \%$ causes the annual growth rate to increase from $2 \%$ to $2.78 \%$. Similarly, when the tax rate is reduced from $20 \%$ to $7.6 \%$, which is the lowest rate for a tax cut deemed as feasible based on the "budget effect" computed previously, the economy's growth rate doubles from $2 \%$ to $4 \%$. As Figure 2 clearly indicates, the magnitude of the growth effect increases with the size of the tax cut $\tau^{0}-\tau^{1}$.

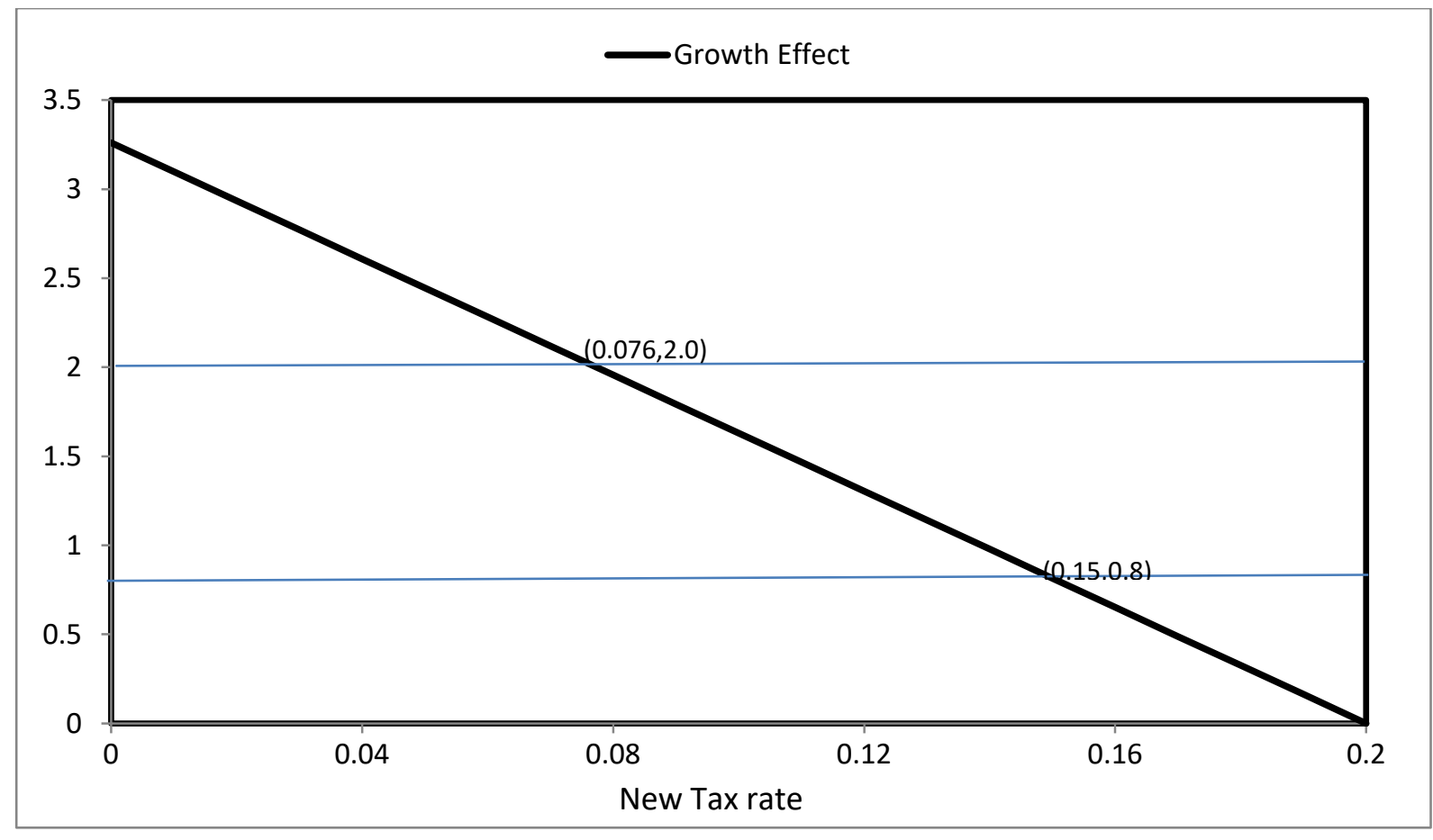

Fig.2. The growth effect in relation to the new tax rate $\tau^{1}=0.15$. The initial tax rate is $\tau^{0}=0.20$. The growth effect measures the increase in the annual growth rate after a tax cut. 


\section{Dynamics of the Budget Deficit and Public Debt}

In this section, we discuss explicitly the dynamics of the budget deficit and public debt following a tax cut. The deficit-to-GDP ratio is given by

$$
\frac{g_{t}^{0}-\tau^{1} A k_{t}^{1}}{A k_{t}^{1}}
$$

Note that the budget deficit in the numerator of this ratio does not include debt interest payments. In other words, it represents the primary budget deficit. Using the parameter values provided in Section 4 and setting $k_{0}=1$, it follows that government transfers are equal to $20 \%$ of output in period 0 and increase by $2 \%$ annually. As calculated in the previous section, a permanent tax cut from $20 \%$ to $15 \%$ increases the growth rate from $2.0 \%$ to $2.8 \%$. Furthermore, the expressions for the evolution of transfers and capital over time imply that the deficit-to-GDP ratio can be computed as

$$
\left(\frac{\text { Deficit }}{G D P}\right)_{t}=\left[\tau^{0}+\frac{b_{0}\left(\gamma^{0}(1+n) R^{0}-1\right)}{A}\right]\left[\frac{R^{0}}{R^{1}}\right]^{\frac{t}{\sigma}}-\tau^{1}
$$

In addition, dividing both sides of equation (7) by output per capita, combining with (15) and substituting backwards to the initial period 0 implies that the debt-to-GDP ratio is given by

$$
\left(\frac{d e b t}{G D P}\right)_{t}=\left[\frac{R^{1}}{(1+n) \gamma^{1}}\right]^{t}\left(\frac{\text { debt }}{G D P}\right)_{0}+\sum_{k=0}^{t-1}\left[\frac{R^{1}}{\left.(1+n) \gamma^{1}\right]}\right]^{t-k}\left(\frac{\text { deficit }}{G D P}\right)_{k}
$$

Following Ireland (1994), we assume that the initial debt per capita is equal to zero $b_{0}=0$. This implies that equations (15) and (16) become

$$
\left(\frac{\text { deficit }}{G D P}\right)_{t}=\tau_{0}\left[\frac{R^{0}}{R^{1}}\right]^{\frac{t}{\sigma}}-\tau^{1}
$$

and 


$$
\left(\frac{d e b t}{G D P}\right)_{t}=\sum_{k=0}^{t-1}\left[\frac{R^{1}}{(1+n) \gamma^{1}}\right]^{t-k}\left(\frac{\text { deficit }}{G D P}\right)_{k} .
$$

Assuming that the tax rate falls from $20 \%$ to $15 \%$ and using the same parameterization as the one outlined in Section 4, Figure 3 depicts the evolution of the deficit-to-GDP ratio over time. It shows that in order to finance the given stream of transfers, the government must run deficits for 37 years, after which the tax base has expanded sufficiently to yield budget surpluses.

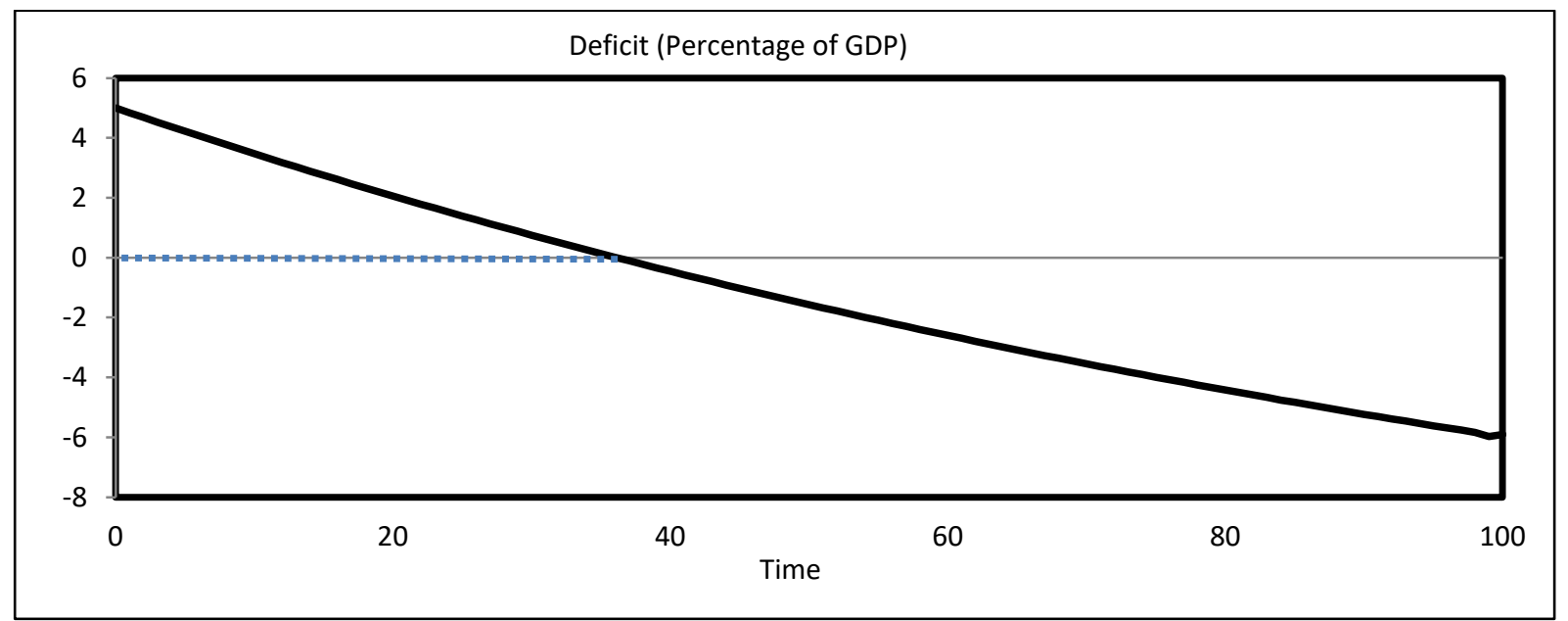

Fig.3. The effects of a tax cut on the budget deficit-to-GDP ratio. The initial rate is $\tau^{0}=0.20$. The new tax rate is $\tau^{1}=0.15$. Time is measured in years.

Government debt outstanding as a share of output is shown in Figure 4. Debt grows to exceed $100 \%$ of GDP, but is completely paid off after 96 years. In fact, the government eventually begins to accumulate private assets (i.e. $B_{t}$ becomes negative), indicating that with a constant tax rate of $15 \%$, the government can actually finance more transfers than it could at the higher rate of $20 \%$. 


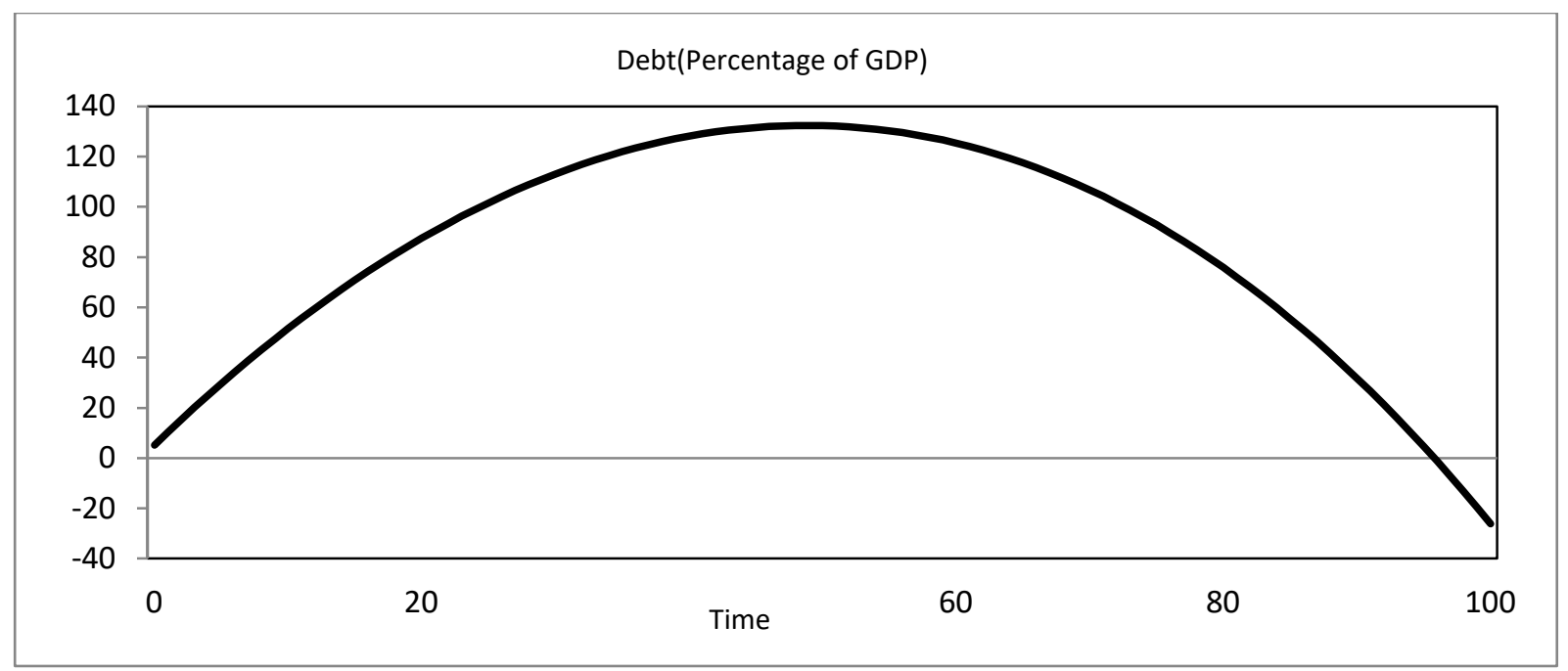

Fig.4. The effects of a tax cut on the debt-to-GDP ratio. The initial tax rate is $\tau^{0}=0.20$. The new tax rate is $\tau^{1}=0.15$. Time is measured in years.

The above simulation results show that a permanent decrease in taxes will contribute to large deficits for almost a century. However, the expansionary effect of lower taxes can actually generate more revenues in the long run than if the government balanced its budget period by period. This means that neither future increases in taxes nor cuts in government spending are necessary to ensure the satisfaction of the government's intertemporal budget constraint. In fact, the expansionary effects of lower taxes are sufficiently large that the government can actually afford to rise spending at some point while taxes are lower than before.

\section{Dynamic Laffer curve and Population Growth}

The previous section replicated the simulation results of Ireland (1994). In this section, we relax his assumption of a constant population and study the impact of population growth on the dynamic Laffer curve effect computed in the numerical results of the previous section. As before, we consider the case of an economy where the initial capital stock per capita is given by $k_{0}=1$ and the tax rate is kept constant. Using the same parameterization as in Sections 4 and 5, it follows that the economy grows by $2 \%$ annually, while transfers represent $20 \%$ of output. The 
budget and growth effects of tax cuts are calculated in the same fashion as before for a reduction in the tax rate from $20 \%$ to $15 \%$. We analyze the results of increasing the population growth rate from zero to $0.5 \%$ and $1 \%$.

\section{a. Budget Effect}

- Case 1: Comparison of $n=0$ [Ireland 1994] with $n=0.005$

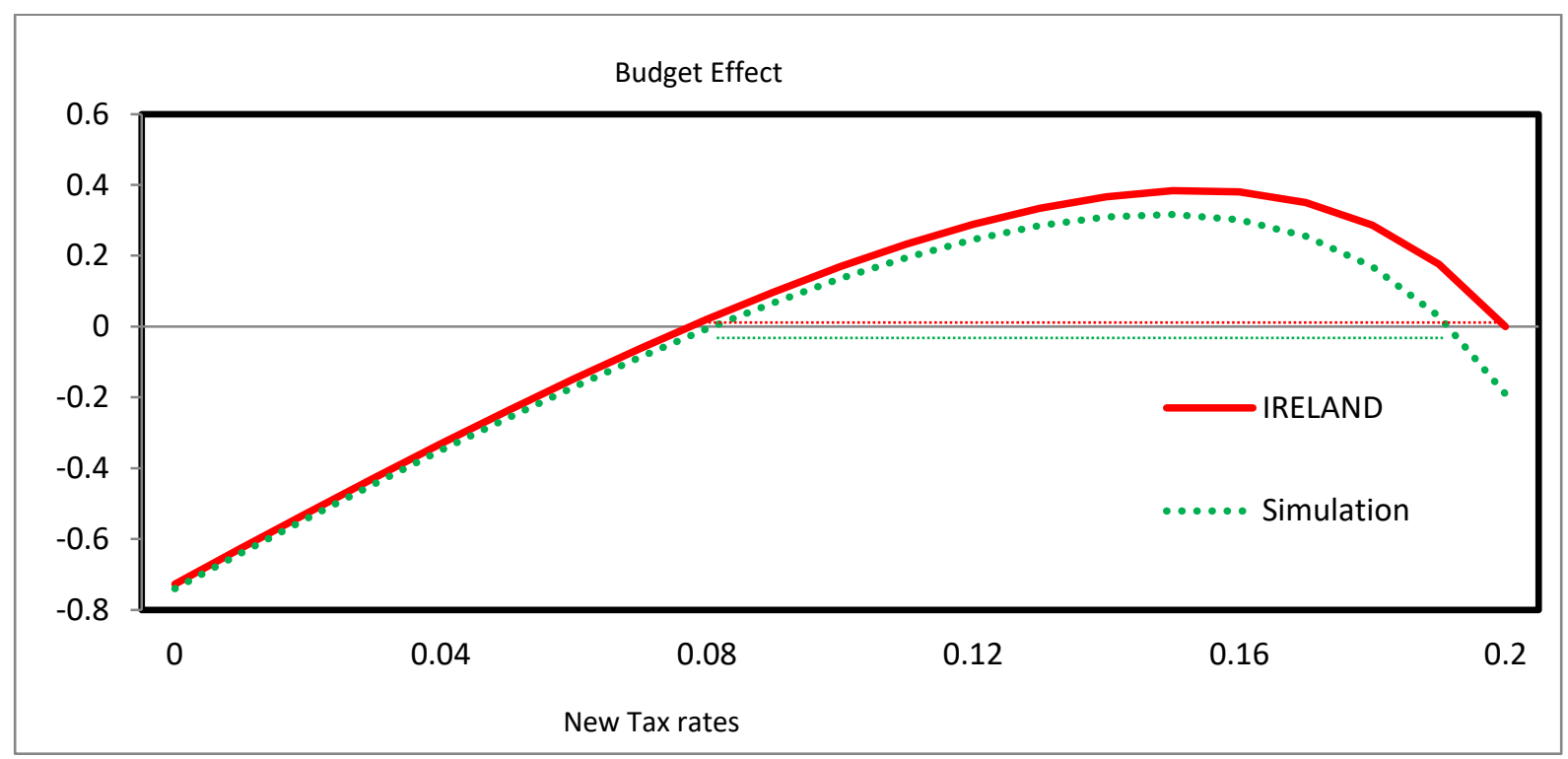

Fig.5. Budget effect analysis between Ireland and simulation: tax cut at 0.15 and population growth at 0.005 and comparing the two cases.

Figure 5 compares the simulation results of Ireland with the case when the population growth rate is at $0.05 \%$. In the case of Ireland, the tax rate can be reduced from $20 \%$ to any rate greater than $7.6 \%$. However, increasing the population growth rate to $0.5 \%$ from $0 \%$ causes the budget effect $L$ curve to shift downwards. Under this new parameterization, the tax rate can be reduced from a maximum of $19 \%$ to any rate greater than $9 \%$. 
- Case 2: Comparison of $n=0$ [Ireland 1994] with $n=0.01$

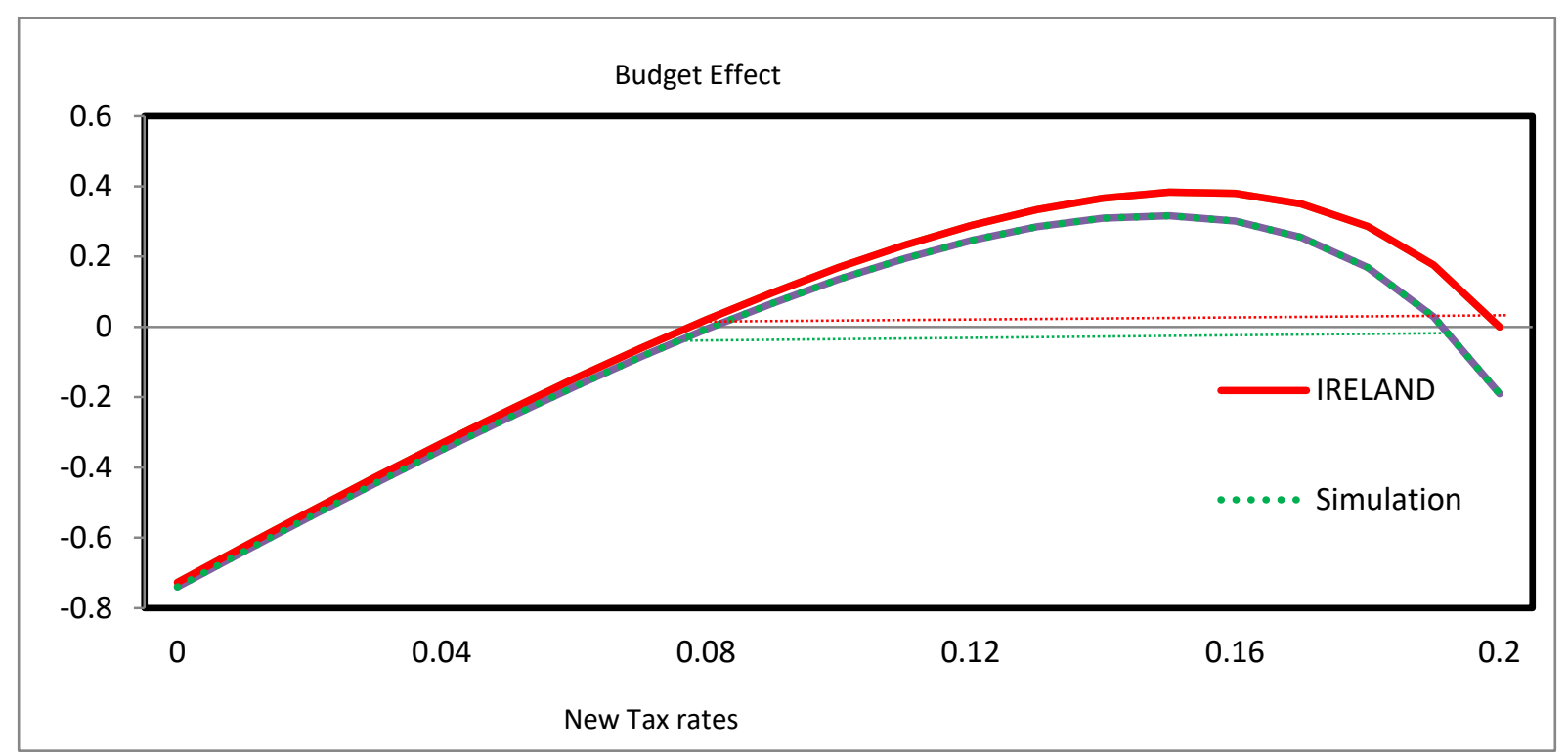

Fig.6. Budget effect analysis between Ireland and simulation: tax cut at 0.15 and population growth at 0.01 and comparing the two cases.

Figure 6 compares the budget effect with a $1 \%$ population growth rate relative to a constant population. In the former case, the impact on the budget effect curve is similar to the in Figure 5. In particular, the budget effect remains positive for any tax rate between $18.9 \%$ to $9.1 \%$.

\section{b. Growth Effect}

- Case 1: Comparison of $n=0$ [Ireland 1994] with $n=0.005$

Figure 7 below compares the growth effect in Ireland's model with the one in our simulation. As shown in the figure, the growth effect is quite similar in both cases for all levels of the tax rate. However, it should be noted that the growth effect with population growth is marginally lower compared to the one with constant population. 


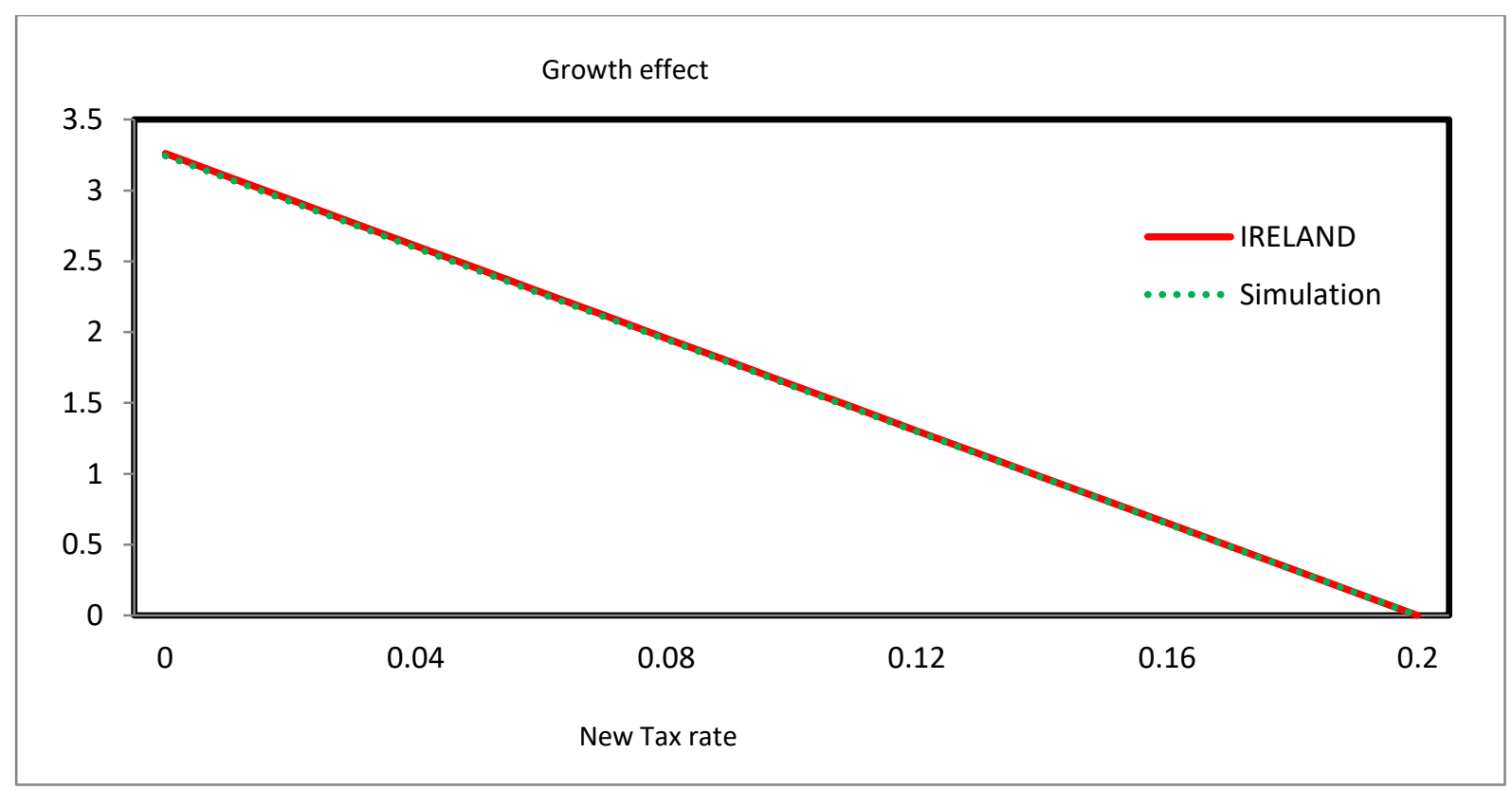

Fig.7. Growth effect analysis between Ireland and simulation: tax cut at 0.15 and population growth at 0.005 and comparing the two cases.

- $\quad$ Case 2: Comparison of $n=0$ [Ireland 1994] with $n=0.01$

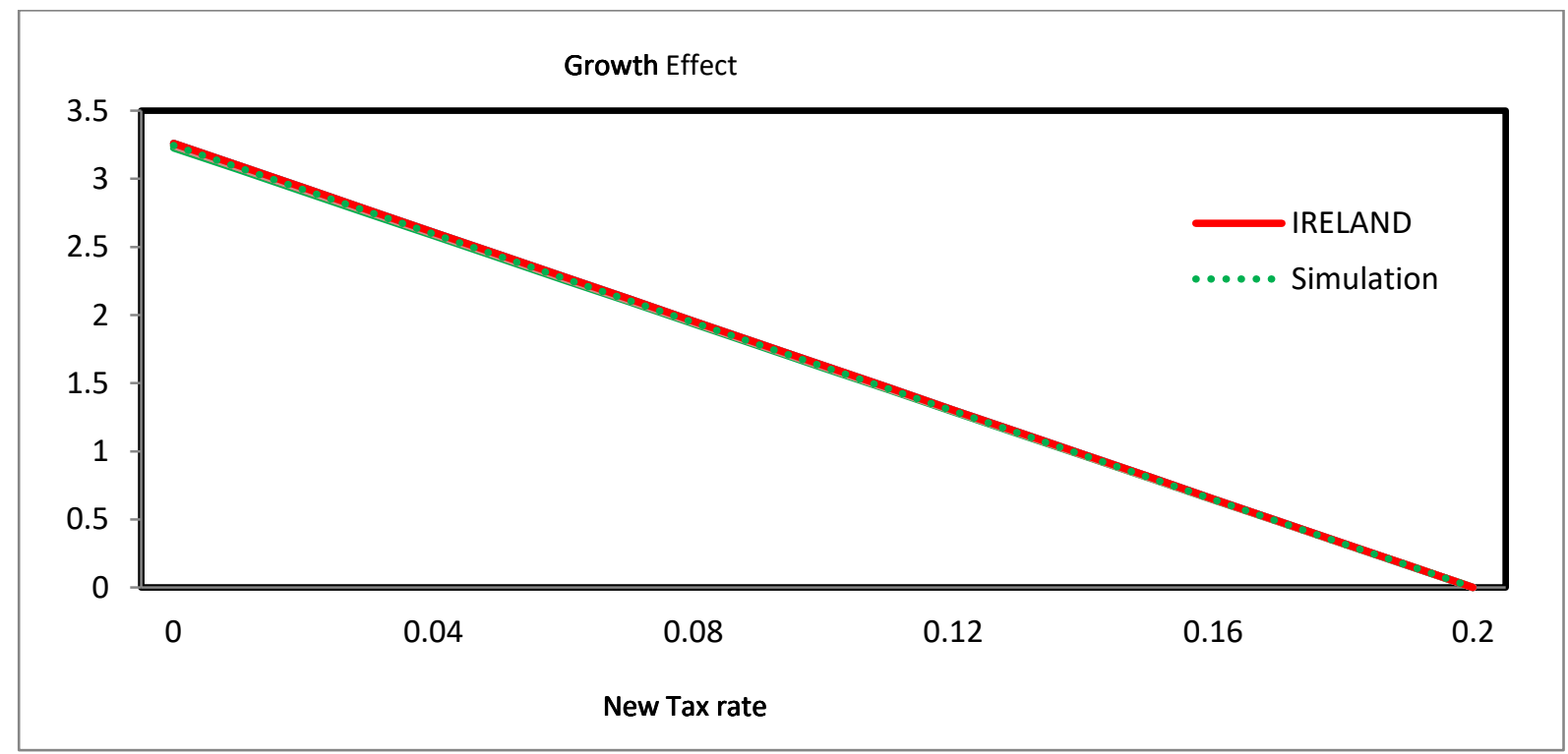

Fig.8. Growth effect analysis between Ireland and simulation: tax cut at 0.15 and population growth at 0.01 and comparing the two cases. 
Relative to the previous figure, we now consider a higher population growth rate: $n=1 \%$. As it was the case previously the growth effect is similar to the one in Ireland's model for all levels of the tax rate. However, the growth effect is still marginally lower relative to the one with constant population and, furthermore, compared to the case with $n=0.5 \%$, this difference has increased.

\section{c. Deficit (Percentage of GDP)}

- Case 1: Comparison of $n=0$ (Ireland 1994) with $n=0.005$ with $b_{0}=0$

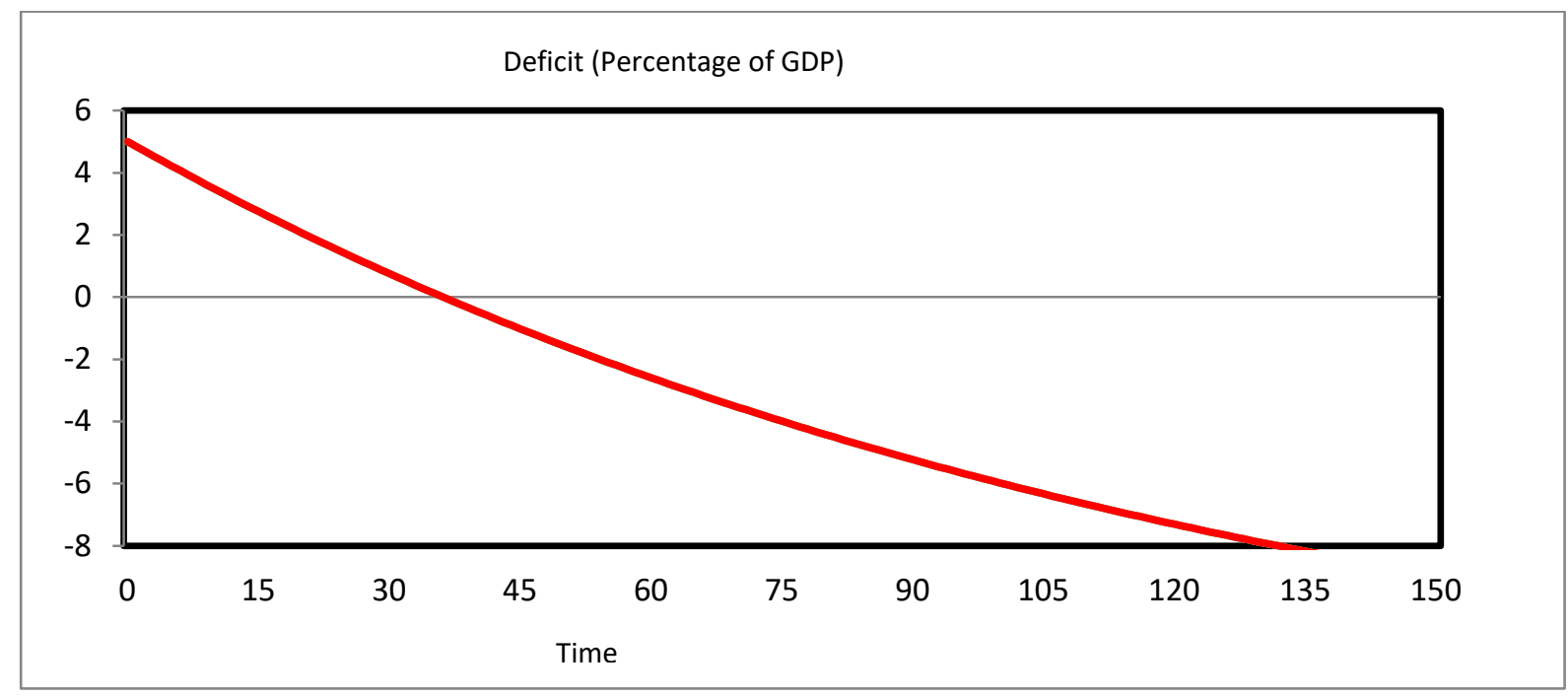

Fig.9. Deficit-to-GDP analysis between Ireland and simulation: tax cut at 0.15 and population growth at 0.005 and comparing the two cases.

Figure 9 plots the deficit-to-GDP ratio in Ireland's model and in ours. As the figure clearly indicates, the two curves coincide. From equation (15), it follows that this is a natural consequence of assuming that $b_{0}=0$. In order to be able to show the effect of population growth on the deficit-to-GDP ratio, we assume that $b_{0}=1$. 
- Case 2: Comparison of $n=0$ (Ireland 1994) with $n=0.005$ with $b_{0}=1$

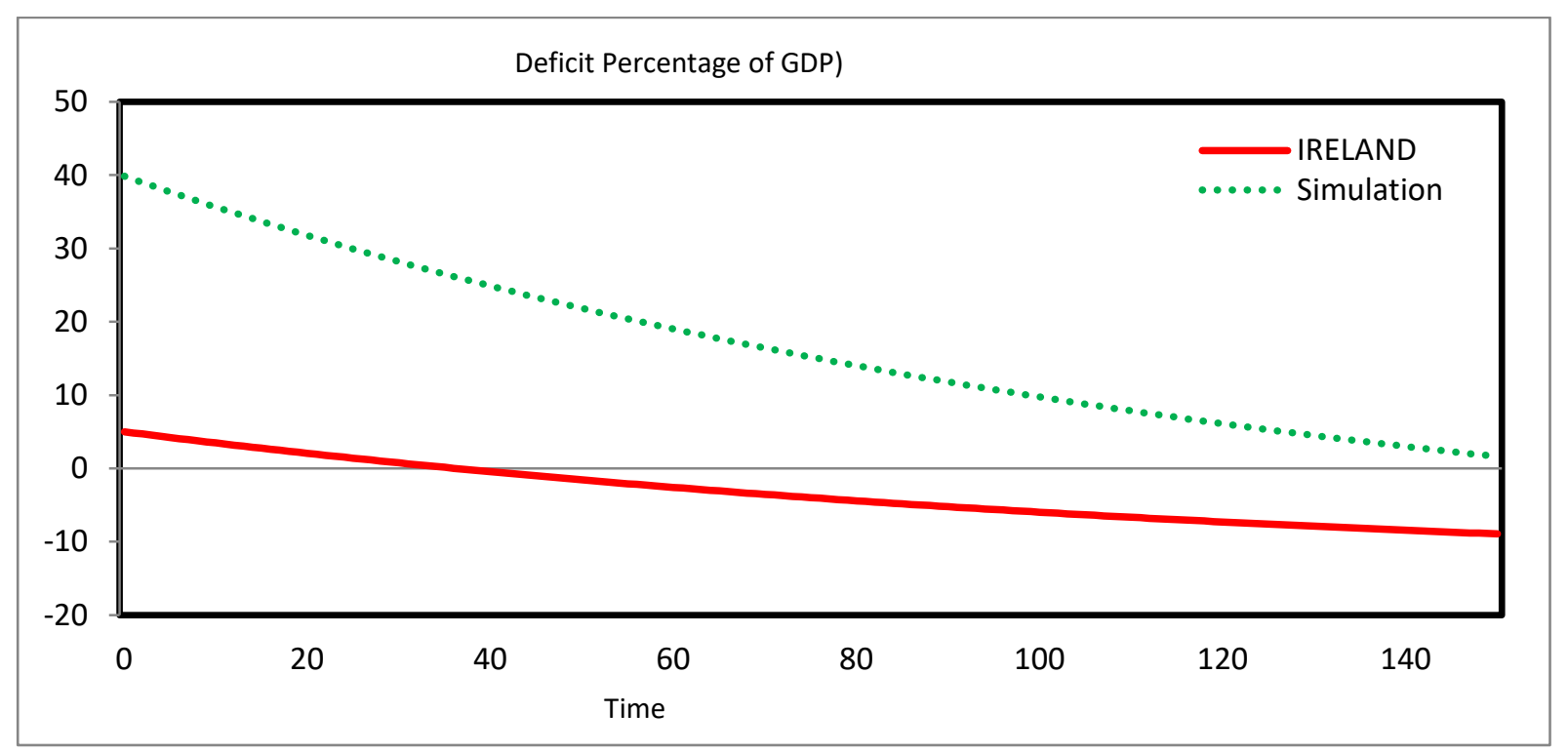

Fig.10. Deficit-to-GDP analysis between Ireland and simulation: tax cut at 0.15 and population growth at 0.005 and comparing the two cases.

Figure 10 plots the deficit-to-GDP in Ireland's model and in ours. Assuming a higher initial debt-per capita has no major impact in Ireland's model: the government runs deficits for 38 years. However, with population growth at $0.5 \%$, the government runs deficits over the entire simulation period of 150 years. Although these deficits will turn to surpluses if the simulation period is extended, the implication is that it will take much longer for the tax cut to pay for itself compared to the case of no population growth.

\section{- Case 3: Comparison of $n=0$ (Ireland 1994) with $n=0.01$}

As it was the case for the previous figure, in order to make a meaningful comparison between our model and Ireland's, we need to assume that $b_{0}$ is different than zero. Figure 11 plots the deficit-to-GDP ratio with constant population and with $n=1 \%$. It shows that the gap between the two curves has widened relative to Figure 10. Therefore, an increase in the 
population growth extends the period in which the government runs budget deficit following the tax cut.

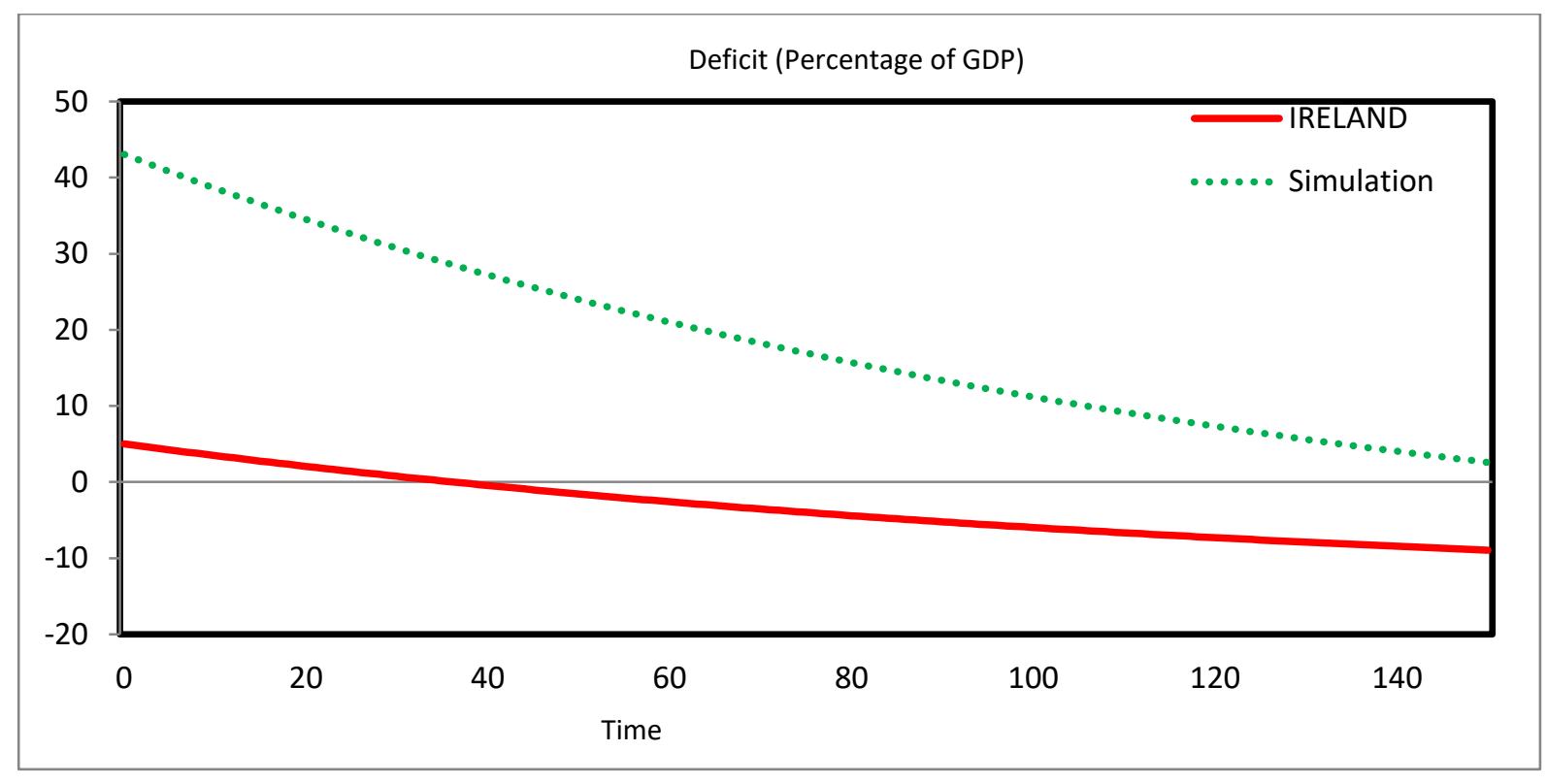

Fig.11. Deficit-to-GDP analysis between Ireland and simulation: tax cut at 0.15 and population growth at 0.005 and comparing the two cases.

\section{d. Debt (Percentage of GDP)}

- Case 1: Comparison of $n=0$ (Ireland 1994) with $n=0.005$

In order to compare the effect of population growth on the debt-to-GDP ratio, we follow Ireland (1994) and assume that $b_{0}=0$. The $5 \%$ reduction in the tax rate causes the government to incur a significant amount of debt relative to the size of the economy with and without population growth. However, this debt is fully paid off in the long run for both cases. As Figure 12 below shows, with a population growth rate of $0.5 \%$ the government needs 110 years to pay off its debt compared to 96 years in Ireland's model. 


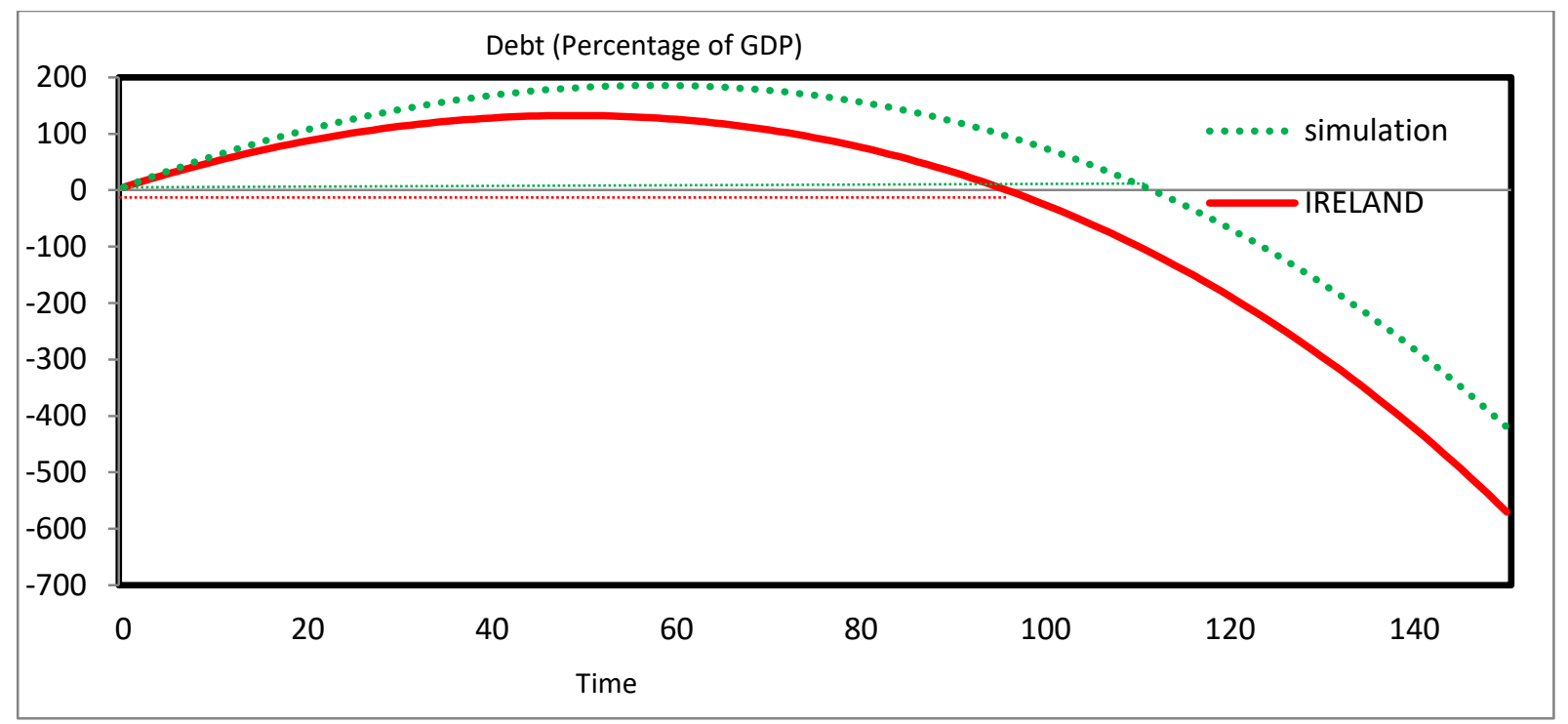

Fig.12. Debt-to-GDP analysis between Ireland and simulation: tax cut at 0.15 and population growth at 0.005 and comparing the two cases.

- Case 2: Comparison of $n=0$ (Ireland 1994) with $n=0.01$

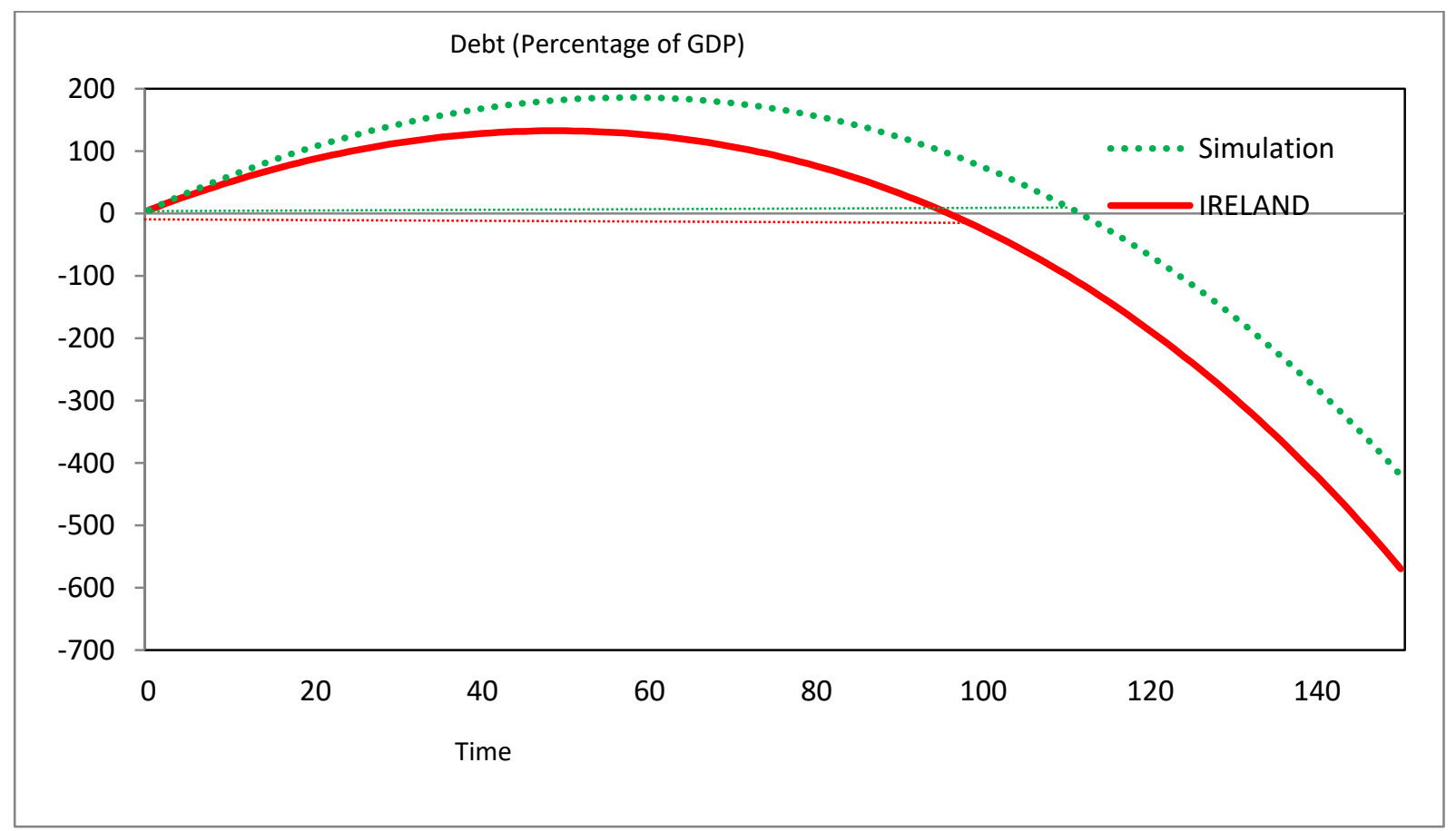

Fig.13. Debt-to-GDP analysis between Ireland and simulation: tax cut at 0.15 and population growth at 0.01 and comparing the two cases. 
Relative to the previous figure, we consider a population growth rate of $1 \%$ instead of $0.5 \%$. The rise in the population growth rate causes the debt-to-GDP curve in our model to shift slightly upwards and to the left. As a consequence, it takes the government case 115 years to pay off its debt compared to 96 years in Ireland's model.

\section{Sensitivity Analysis}

In addition to studying the sensitivity of Ireland's results with respect to population growth, we also consider the impact of the value of the intertemporal elasticity of substitution. Note that the elasticity of the growth rate $\gamma$ with respect to the after-tax return on capital $R$ is $1 / \sigma$. It follows that the growth effect from a given tax cut decreases in $\sigma$. Furthermore, the budget effect $L$ is also decreasing in $\sigma$. These results are confirmed in the simulations presented below.

\section{a. Budget Effect}

- $\quad$ Case 1: Comparison of $n=0, \sigma=1$ [Ireland 1994] with $n=0, \sigma=1.1$

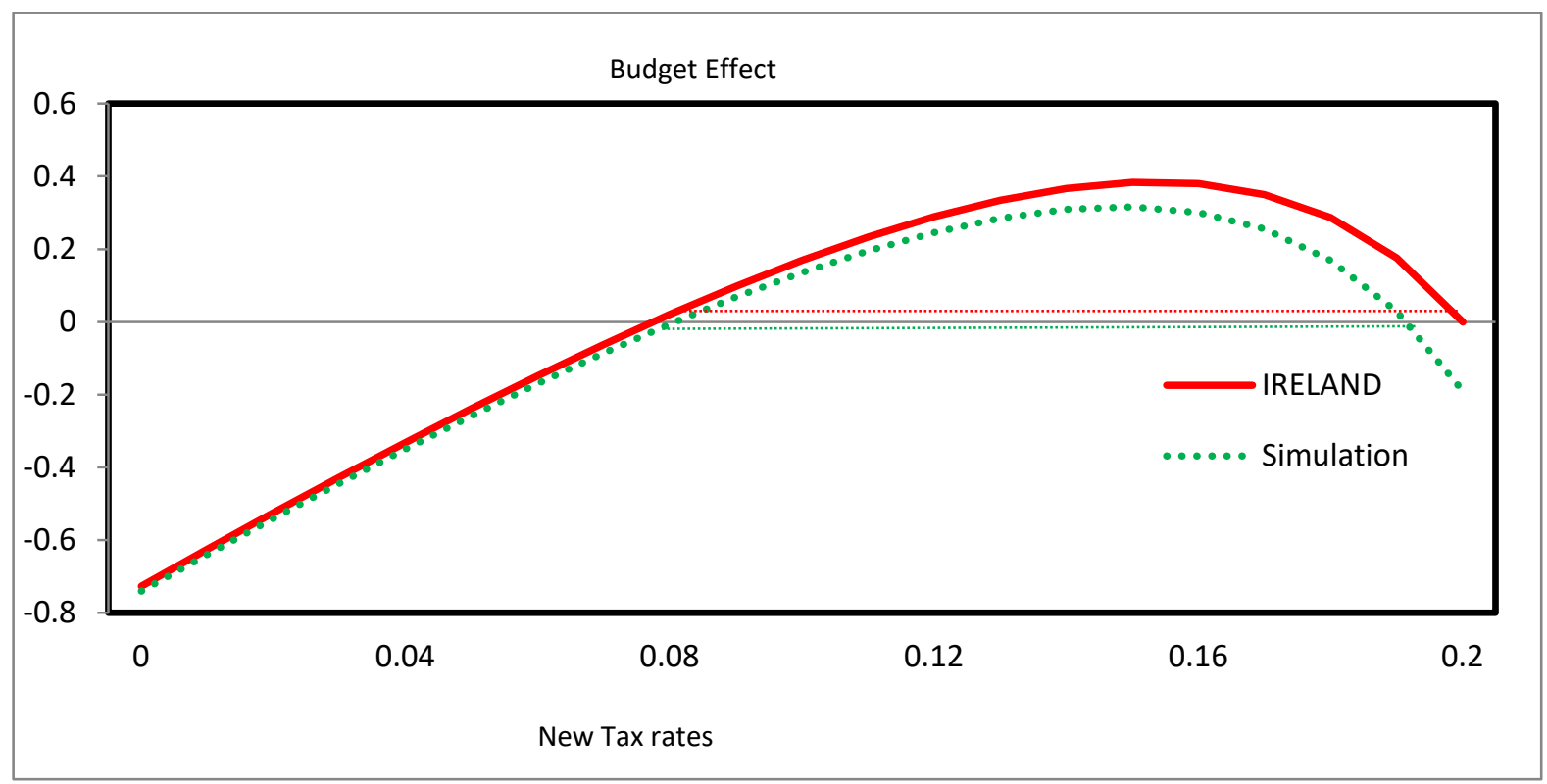

Fig.14. Budget effect between Ireland and simulation with tax cut, changing sigma and comparing the two cases. 
Figure 14 draws the comparison between Ireland's results and our simulation results based on a higher value of the intertemporal elasticity of substitution. In particular, we assume that the value of this elasticity is 1.1 . In the case of Ireland, the budget effect $L$ is positive for all new tax rates $\tau^{1}$ greater than 0.076 . Thus, the tax rate can be reduced from its calibrated value of $20 \%$ to any rate greater than $7.6 \%$ while still balancing the government's present value budget constraint in the long run. However, when we change the intertemporal elasticity to 1.1 , the budget effect is positive for any values between 0.08 and 0.19 . Thus, the tax rate can be reduced from a maximum rate of $19 \%$ to any rate greater than $8 \%$.

- $\quad$ Case 2: Comparison of $n=0, \sigma=1$ [Ireland 1994] with $n=0.005, \sigma=1.1$

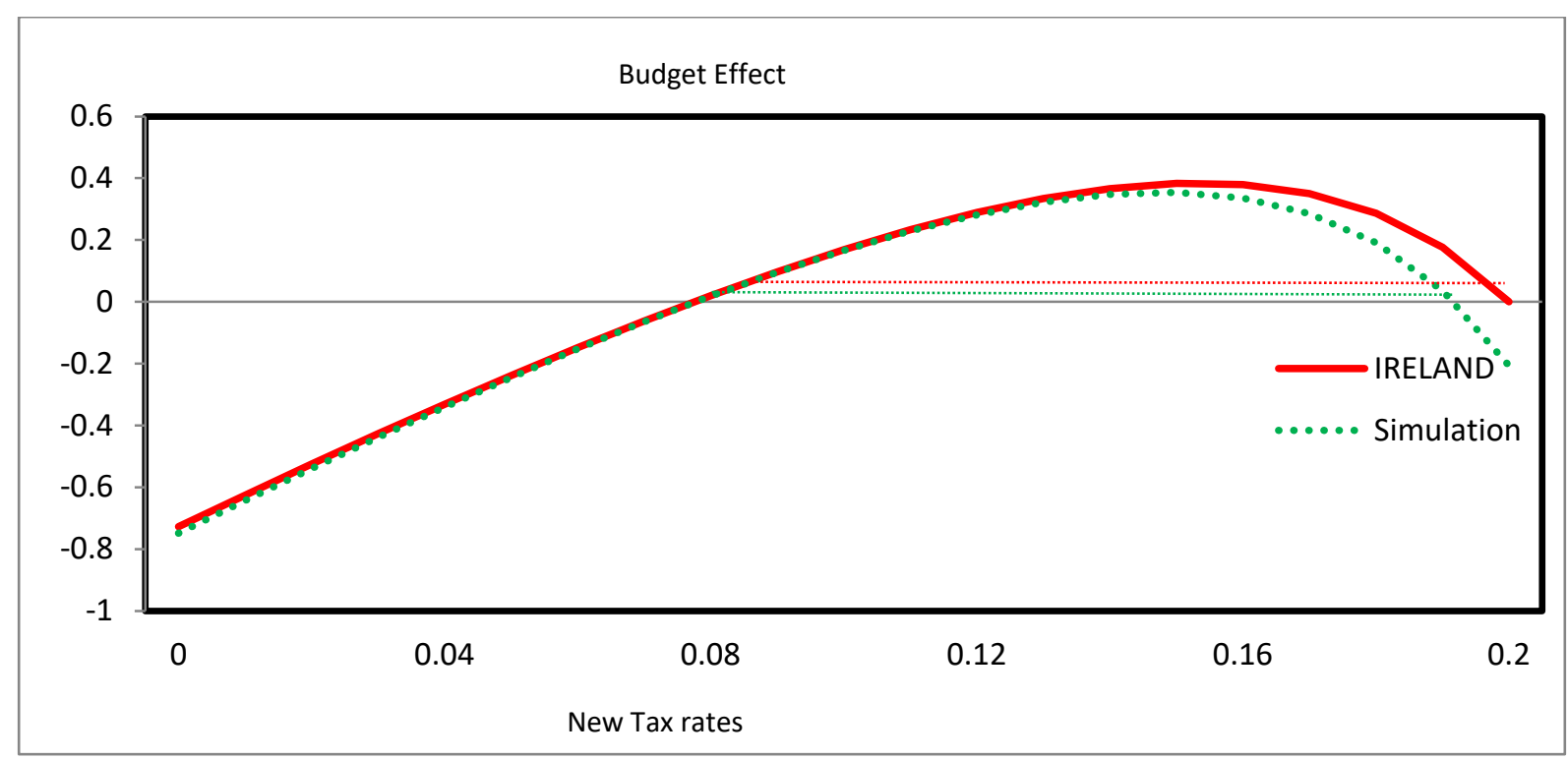

Fig.15. Budget effect analysis between Ireland and simulation: tax cut, population growth, changing sigma and comparing the two cases.

Figure 15 compares the simulation results of Ireland with the case when the population growth rate is 0.005 and the intertemporal elasticity is 1.1. As mentioned previously, in the case of Ireland, the tax rate can be reduced from $20 \%$ to any rate greater than $7.6 \%$. However, when we 
consider a non zero population growth rate and an intertemporal elasticity of substitution greater than 1 , then the budget effect $L$ curve shifts downwards. Under this new parameterization, the tax rate can be reduced from a maximum of $19 \%$ to any rate greater than $8 \%$ while the budget effect still remain positive.

- $\quad$ Case 3: Comparison of $n=0, \sigma=1$ [Ireland 1994] with $n=0.01, \sigma=1.1$

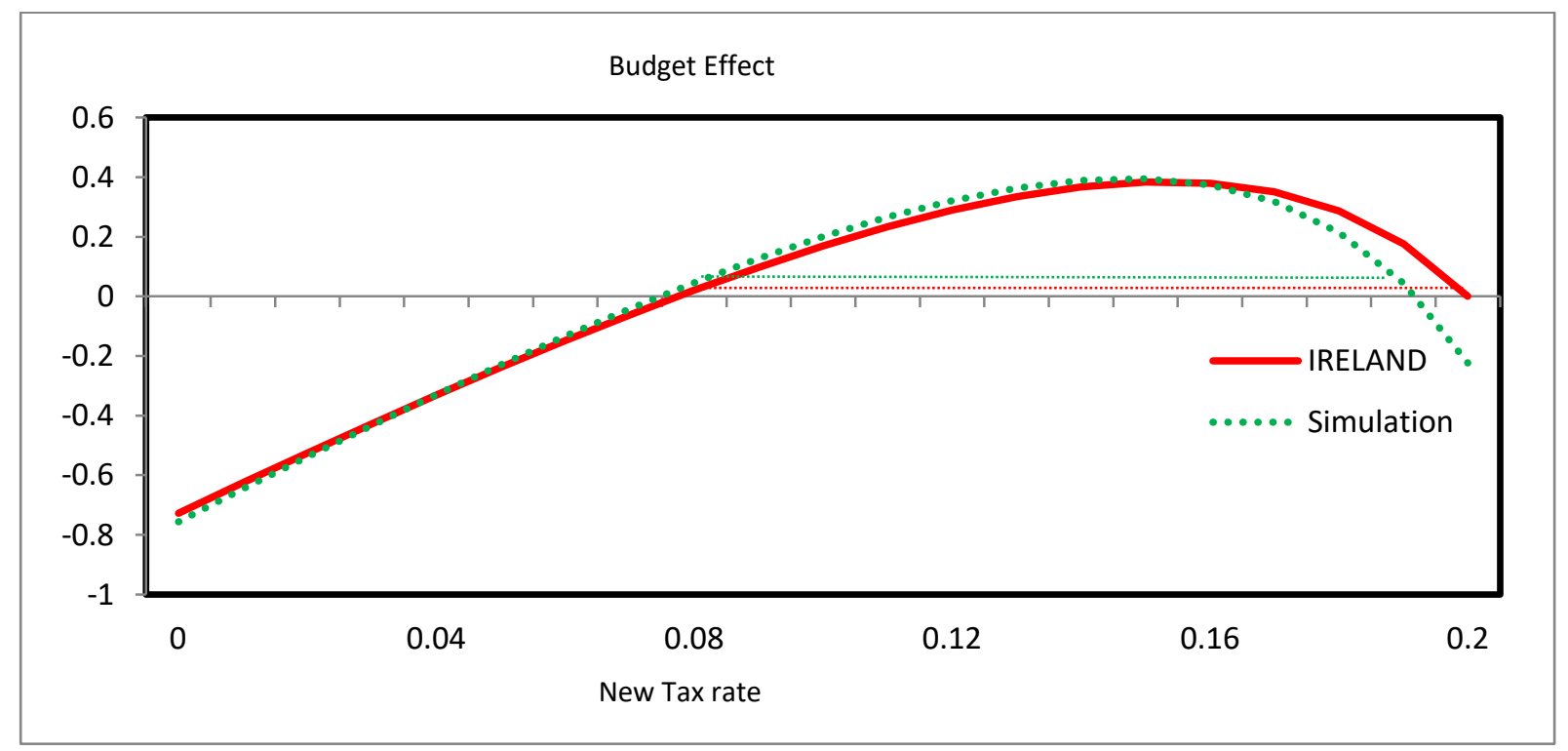

Fig.16. Budget effect analysis between Ireland and simulation: tax cut, population growth, changing sigma and comparing the two cases.

Figure 16 compares the simulation results of Ireland with the case when the population growth rate is 0.01 and the intertemporal elasticity is 1.1. As mentioned previously, in the case of Ireland, the tax rate can be reduced from $20 \%$ to any rate greater than $7.6 \%$. However, when the population growth rate is $1 \%$ instead of zero and the intertemporal elasticity of substitution is equal to 1.1 instead of one, then the budget effect $L$ curve becomes less dispersed and tilts slightly upwards. Under the new parameterization we consider, the tax rate can be reduced from a highest possible value of roughly $19 \%$ to any rate greater than $8 \%$ while the budget effect is still positive. 


\section{b. Growth Effect}

- $\quad$ Case 1: Comparison of $n=0, \sigma=1$ [Ireland 1994] with $n=0, \sigma=1.1$

Figure 17 below describes the growth effect for alternative values of $\tau^{1}$ keeping all other parameter values fixed while considering Ireland's case. The growth effect is positive in Ireland's model as well as in our simulation where we consider a value of the intertemporal elasticity of substitution of 1.1. However, for every level of the tax rate, the growth effect in our simulations is lower compared to Ireland's with the gap widening as the value of the new tax rate is smaller. A reduction in the tax rate from $20 \%$ to $15 \%$ generates a growth effect of $0.81 \%$ in Ireland's case while in our simulation this effect is $0.73 \%$.

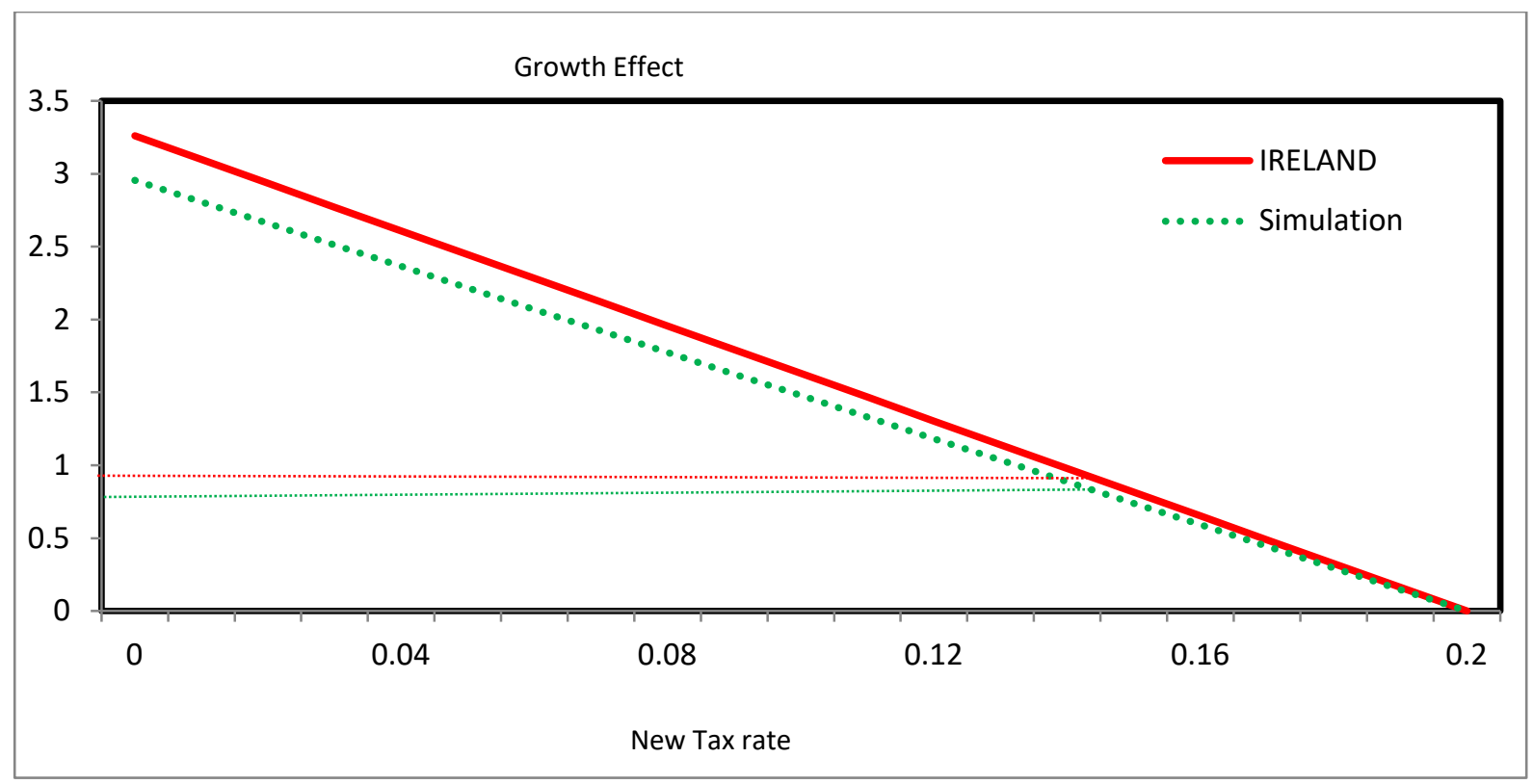

Fig.17. Growth effect analysis between Ireland and simulation: tax cut, changing sigma and comparing the two cases. 
- $\quad$ Case 2: Comparison of $n=0, \sigma=1$ (Ireland 1994) with $n=0.005, \sigma=1.1$

Similar to the previous figure, Figure 18 below displays the growth effect for alternative values of $\tau^{1}$. The difference is that now the population growth rate is equal to $0.5 \%$ instead of zero.

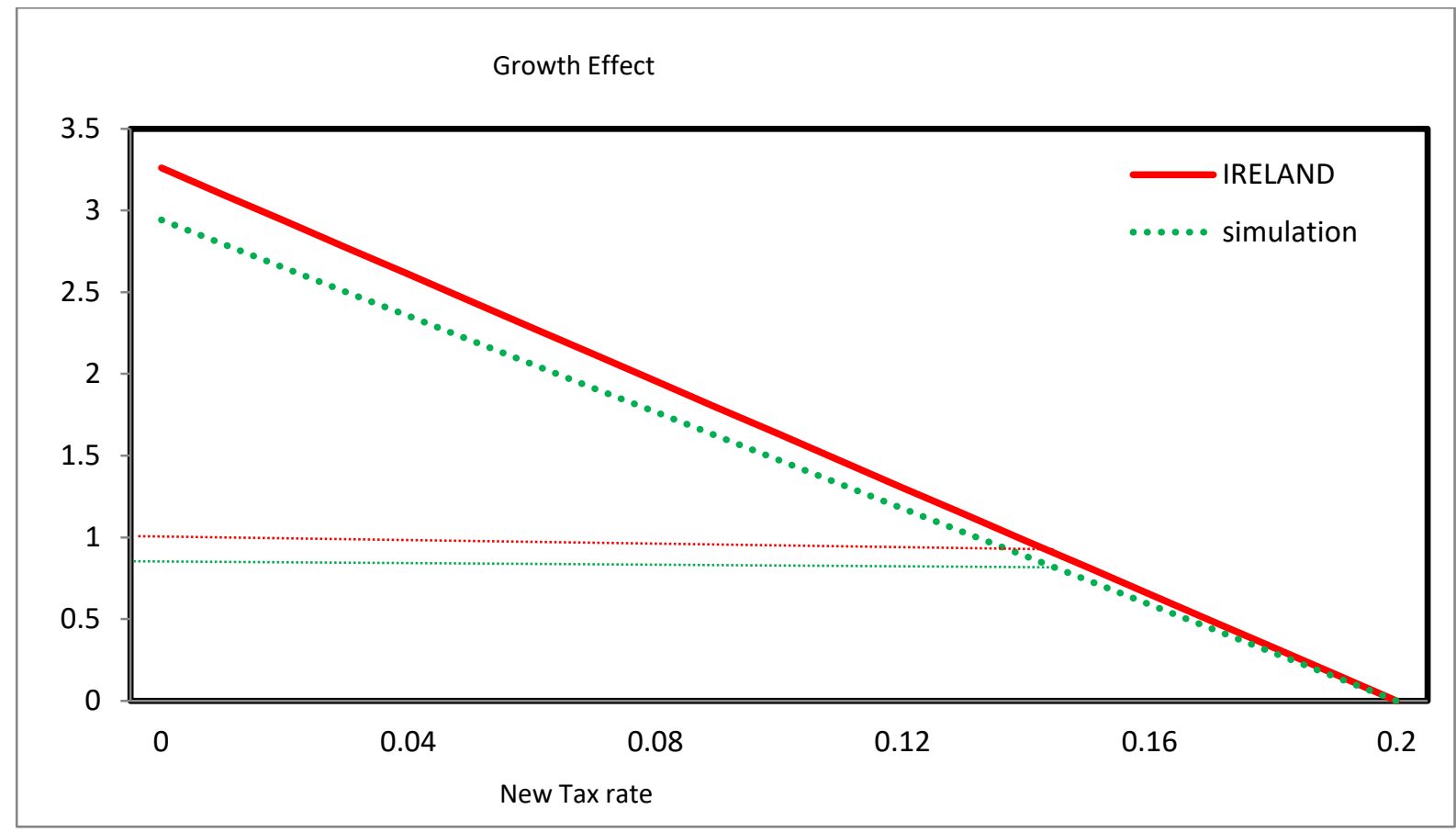

Fig.18. Growth effect analysis between Ireland and simulation: tax cut, population growth, changing sigma and comparing the two cases.

The growth effect is positive in Ireland as well as in our simulation where we consider a value of the intertemporal elasticity of substitution of 1.1. The pattern is the same as in Figure 17 with the gap of the growth effect for the present parameterization and Ireland's widening as the value of the new tax rate becomes smaller. A reduction in the tax rate from $20 \%$ to $15 \%$ generates a growth effect of $0.81 \%$ in Ireland's case while in our simulation this effect is $0.731 \%$. 
- Case 3: Comparison of $n=0, \sigma=1$ (Ireland 1994) with $n=0.01, \sigma=1.1$

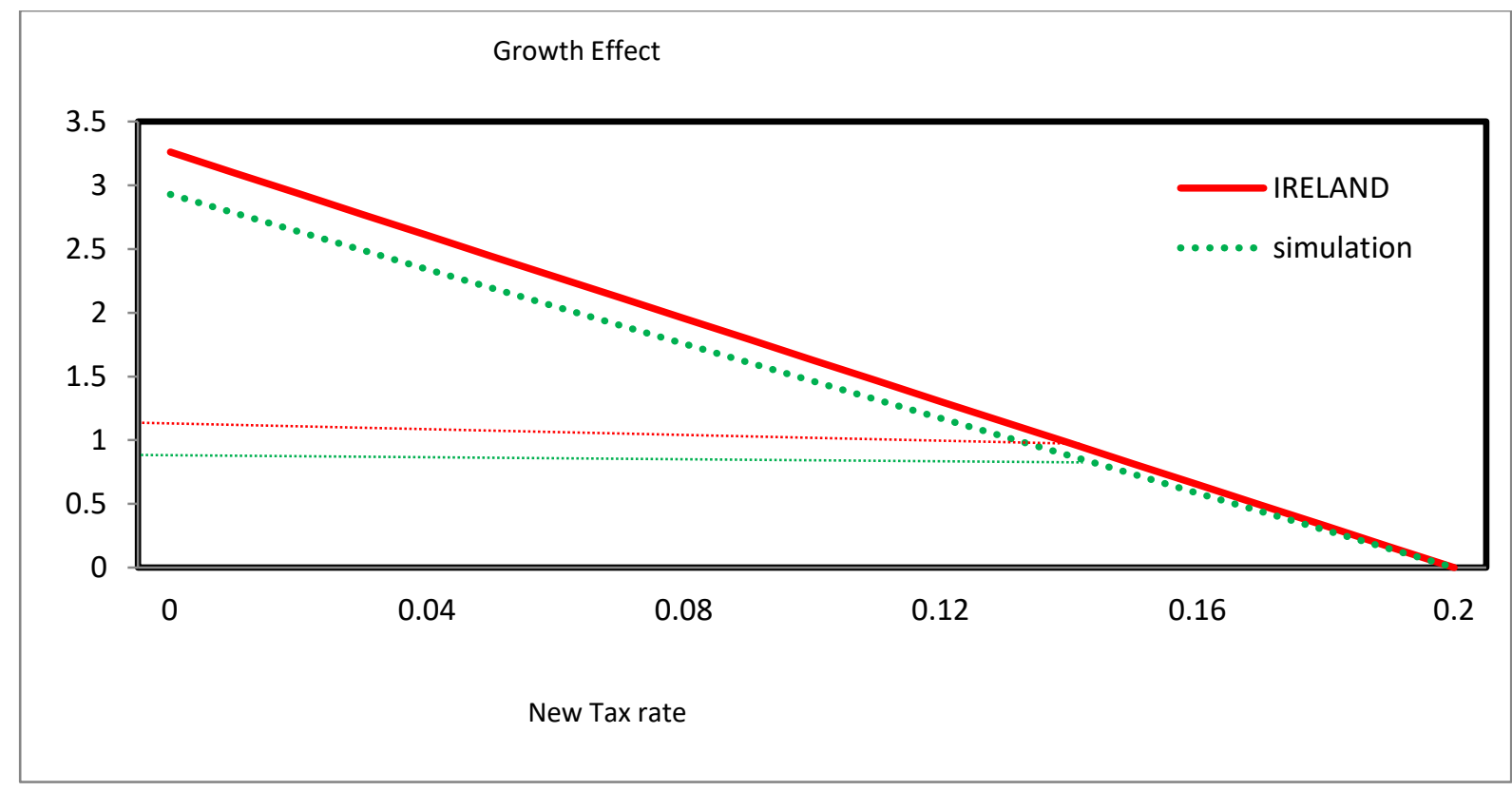

Fig.19. Growth effect analysis between Ireland and simulation: tax cut, population growth, changing sigma and comparing the two cases.

Relative to the previous figure, we now consider a higher population growth rate: $n=1 \%$. Comparing Figure 19 above with Figure 18, it becomes clear that the gap in the growth effect relative to Ireland's model becomes smaller as the population growth rate increases. A reduction in the tax rate from $20 \%$ to $15 \%$ generates a growth effect of $0.81 \%$ in Ireland's case while in our simulation this effect is $0.732 \%$.

\section{c. Deficit (Percentage of GNP)}

- Case 1: Comparison of $n=0, \sigma=1$ (Ireland 1994) with $n=0, \sigma=1.1$

Figure 20 below depicts the evolution of the deficit-to-GDP ratio over time assuming that the government reduces the tax rate from $20 \%$ to $15 \%$. 


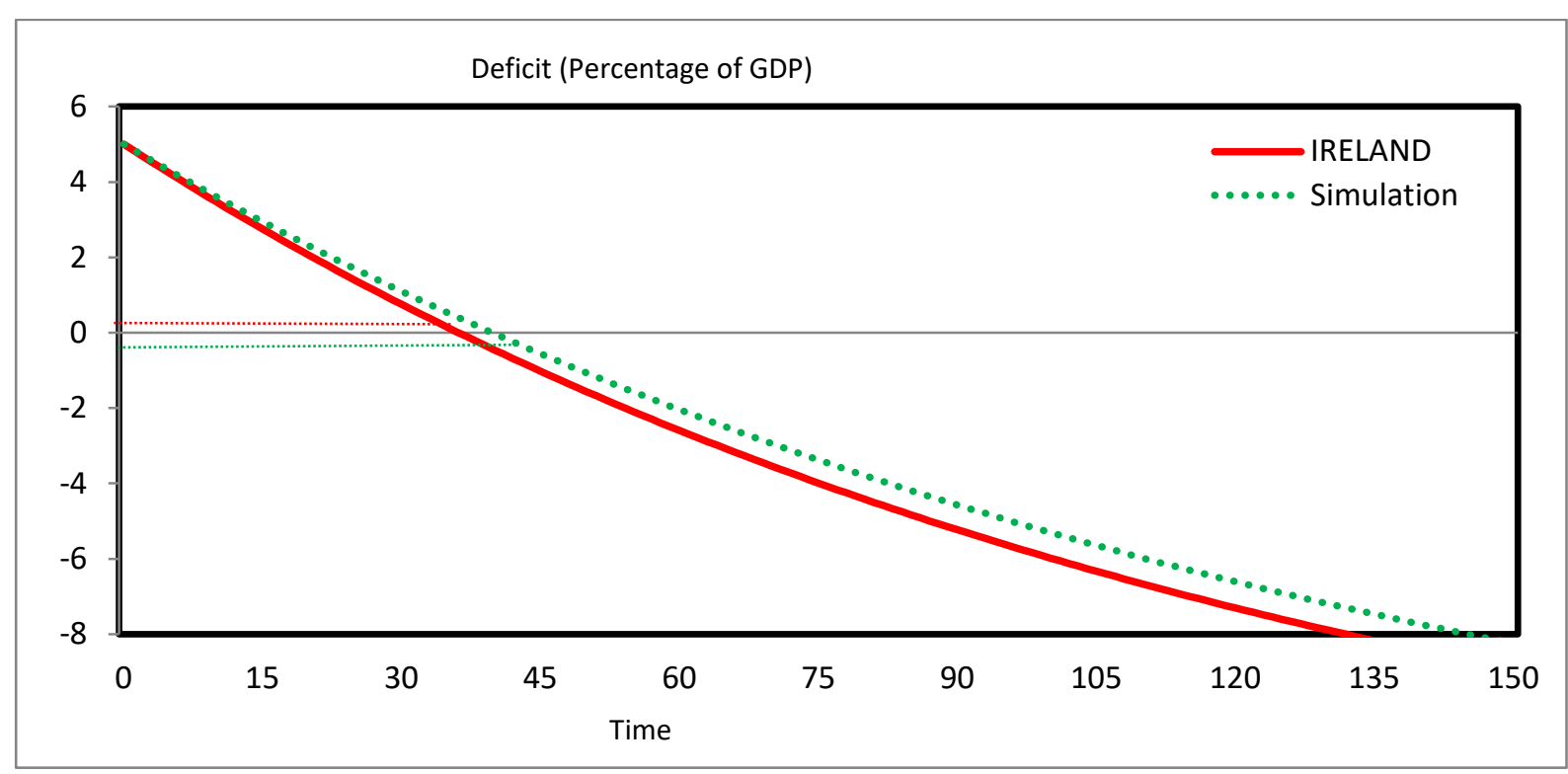

Fig.20. Deficit effect analysis between Ireland and simulation: tax cut, population growth, changing sigma and comparing the two cases.

In Ireland's case, the government runs budget deficits for 37 years, after which the tax base has expanded sufficiently to yield budget surpluses. In contrast, raising the value of $\sigma$ from 1.0 to 1.1 implies that the government will have to run deficits for three additional years.

- Case 2: Comparison of $n=0, \sigma=1$ (Ireland 1994) with $n=0.005, \sigma=1.1$

Relative to the previous figure, we now assume that the population growth rate is $0.5 \%$ instead of zero and compare our simulation results with Ireland's. As it is shown in Figure 21, the government incurs a deficit for a total of 40 years before starting to accumulate budget surpluses. In contrast, the government's shortfall in Ireland's model lasts for 37 years. 


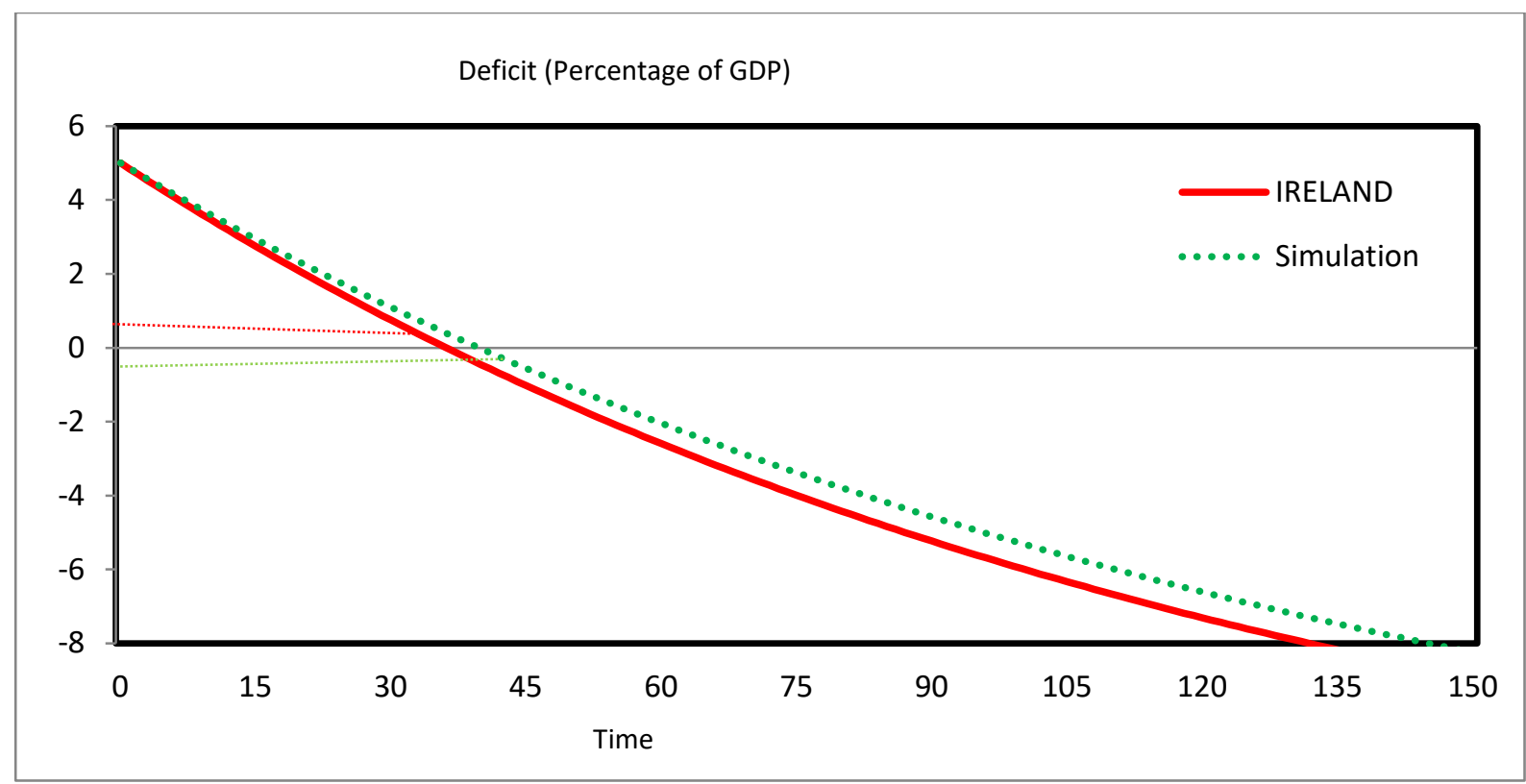

Fig.21. Deficit effect analysis between Ireland and simulation: tax cut, population growth, changing sigma and comparing the two cases.

- $\quad$ Case 3: Comparison of $n=0, \sigma=1$ (Ireland 1994) with $n=0.01, \sigma=1.1$

Finally, in Figure 22 below we consider a population growth rate of $1 \%$. In this case, the government runs budget deficits for 39 years instead of 40 when the population growth rate was assumed to be $0.5 \%$. 


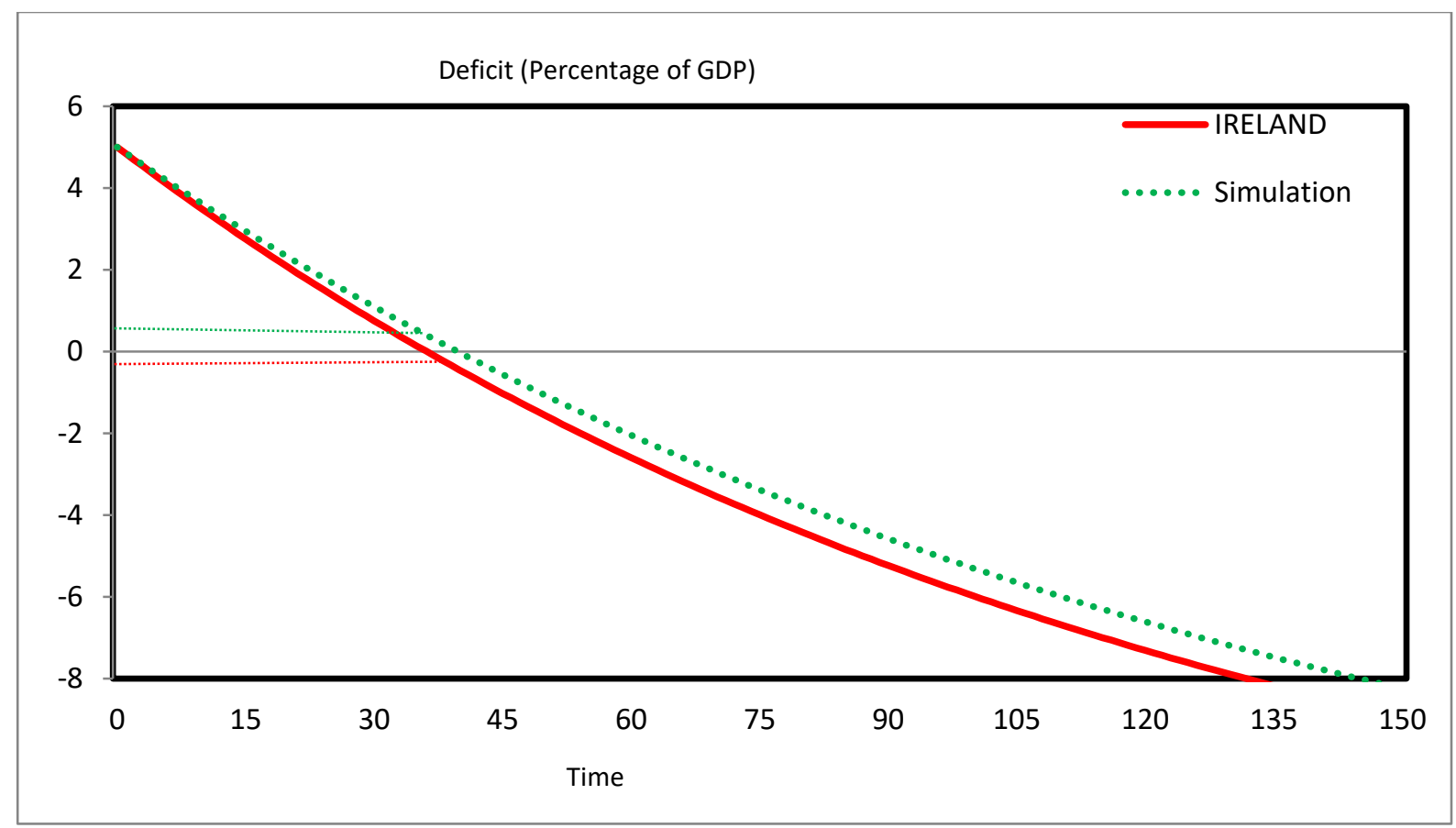

Fig.22. Deficit effect analysis between Ireland and simulation: tax cut, population growth, changing sigma and comparing the two cases.

\section{d. Debt (Percentage of GDP)}

- Case 1: Comparison of $n=0, \sigma=1$ (Ireland 1994) with $n=0, \sigma=1.1$

Figure 23 below depicts the evolution of the debt-to-GDP ratio over time assuming that the government reduces the tax rate from $20 \%$ to $15 \%$. Recall that Ireland shows that a permanent decrease in taxes will contribute to large deficits for many years. However, the expansionary effects of lower taxes can actually generate more revenues. This means that the expansionary effects of lower taxes are sufficiently large that the government can actually afford to rise spending at some point while taxes are lower than before. In Ireland's case, it takes the government 96 years to pay off its debt. In contrast, raising the value of $\sigma$ from 1.0 to 1.1 implies that the government will need a total of 111 years instead. 


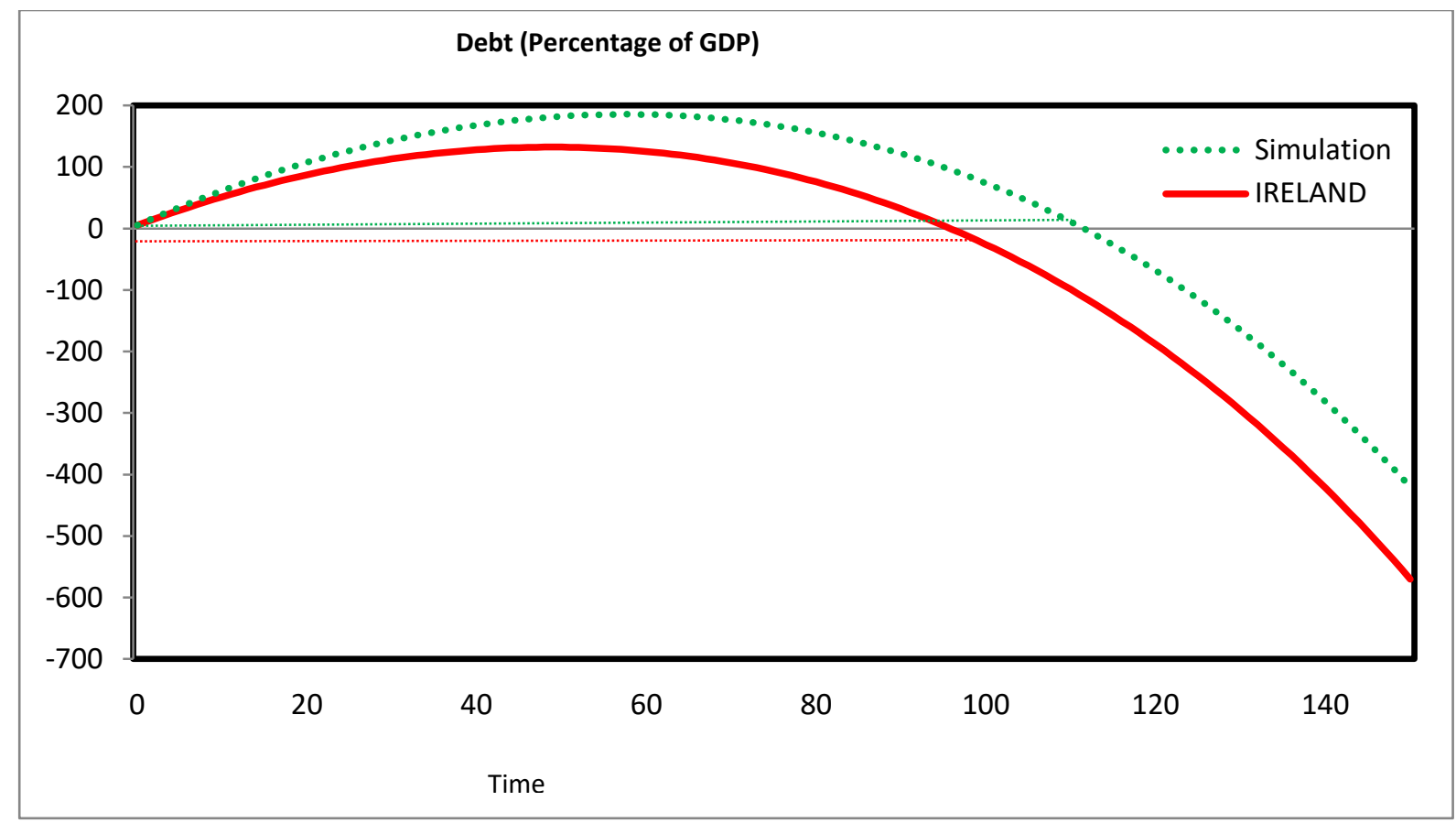

Fig.23. Debt effect analysis between Ireland and simulation: tax cut, changing sigma and comparing the two cases.

- Case 2: Comparison of $n=0, \sigma=1$ (Ireland 1994) with $n=0.005, \sigma=1.1$

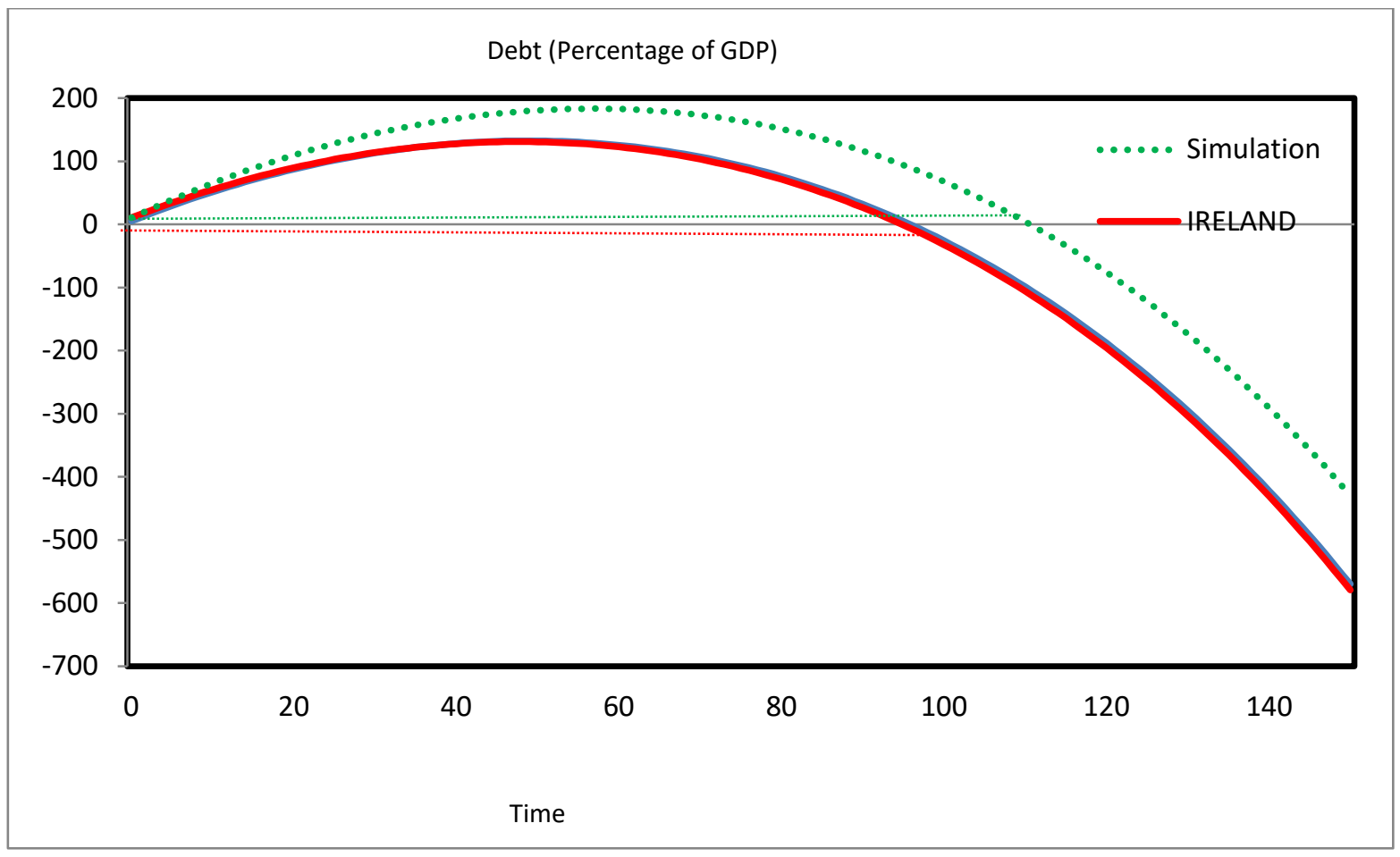

Fig.24. Debt effect analysis between Ireland and simulation: tax cut, population growth, changing sigma and comparing the two cases. 
Relative to previous figure, we now assume that the population growth rate is equal to $0.5 \%$ instead of zero. As Figure 24 above shows, under this parameterization, the government needs 110 to pay off its debt compared to 96 years in Ireland's model.

- Case 3: Comparison of $n=0, \sigma=1$ (Ireland 1994) with $n=0.01, \sigma=1.1$

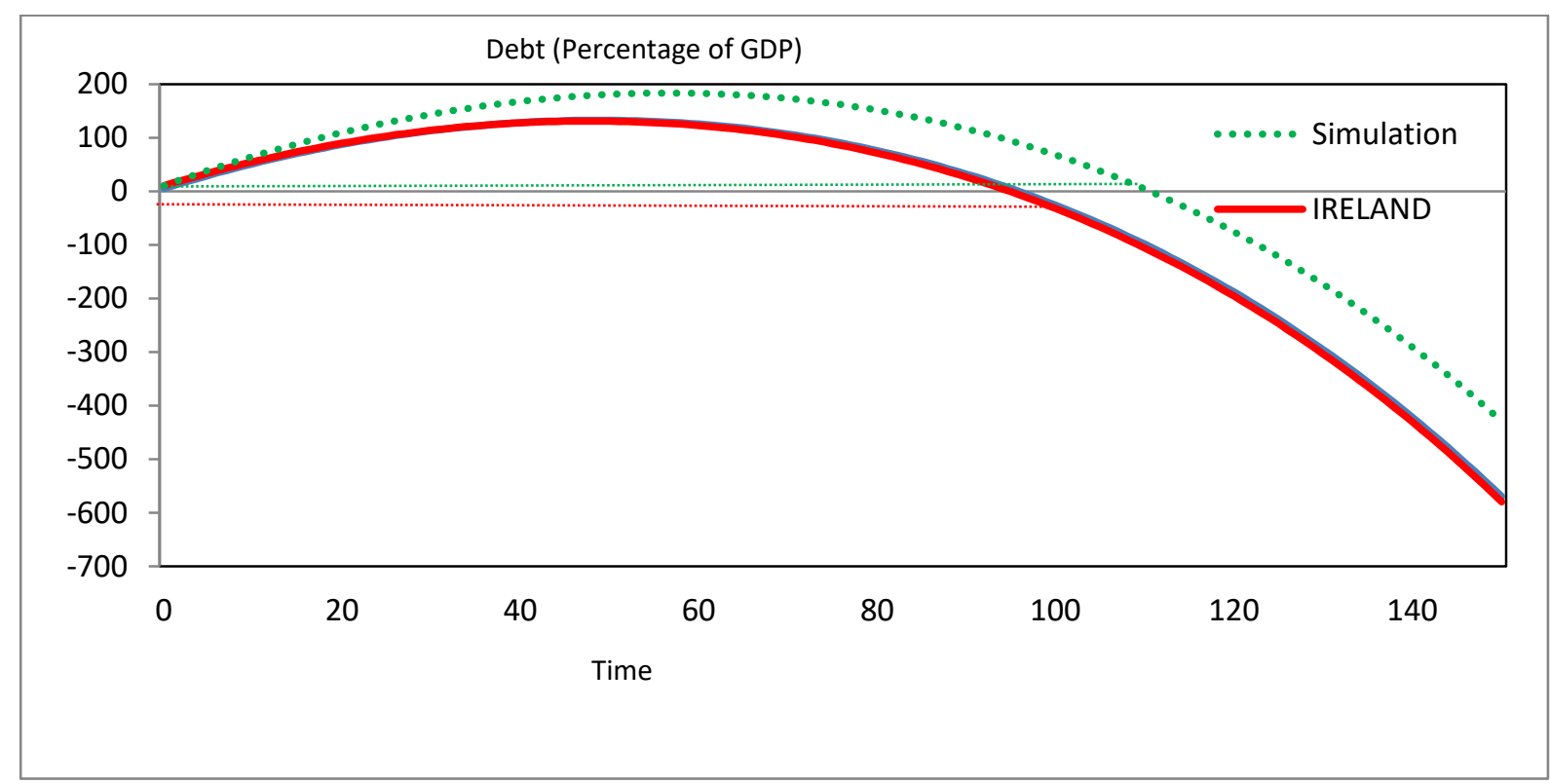

Fig.25. Debt effect analysis between Ireland and simulation: tax cut, population growth, changing sigma and comparing the two cases.

Finally, we consider a population growth rate of $1 \%$. As it shown in Figure 25 above, it takes the government in this case 112 years to pay off its debt compared to 96 years in Ireland's model.

\section{Conclusion}

We have investigated whether the dynamic Laffer curve effect occurs with the population growth and change in the intertemporal elasticity under a set of reasonable parameter values. To compare and contrast our results with those of Ireland (1994), the initial tax rate, new tax rate, population growth and change in intertemporal elasticity were discussed and analyzed under 
sensitivity analysis with population growth only and with the change in intertemporal elasticity.

The value of $\sigma$ played a crucial role in determining whether there exists effects of population growth on the budget effect, growth effect, deficit and debt (percentage of GDP). It is noted that the population growth has negative impact on the growth effect. The budget effect $L$ curve tilts slightly downwards. However, the tax rate can be reduced from a highest possible value of roughly $19 \%$ to any rate greater than $8 \%$ while the budget effect is still positive. We examine the deficit (as a percentage of GDP) and debt (as percentage of GDP) to see how long the government takes to repay its debt with population growth. In Ireland's case, it runs a deficit for 37 years and the same is observed with population growth at $0.5 \%$ and $1 \%$ at $b_{0}=0$. However, to see the effect of deficit, we observe deficit(as a percentage of GDP)at $b_{0}=1$. Finally, when we study debt (as a percentage of GDP) with population growth rate of $0.5 \%$ and $1 \%$, we find that it takes the government longer to pay off its debt compared to 96 years in Ireland's model.

\section{Appendix A:}

\section{A1. Consumer's Budget Constraint in period $t$ :}

$$
\begin{gathered}
\mathcal{L}=\sum_{t=0}^{\infty} \beta^{t}\left[\frac{C_{t}^{1-\sigma}-1}{1-\sigma}\right]+\lambda_{t}\left[(1-\tau) A k_{t}+(1-\delta) k_{t}+b_{t}+g_{t}-c_{t}-(1+n) k_{t+1}\right. \\
\left.-(1+n)\left\{\left(b_{t+1}\right) / R_{t}\right\}\right] .
\end{gathered}
$$

Take the first Order derivative with respect to $C_{t}$,

$$
\begin{aligned}
& \frac{\partial \mathcal{L}}{\partial C_{t}}=0 . \\
& \Rightarrow \beta^{t}\left\{C_{t}^{-\sigma}-\lambda_{t}\right\}=0 . \\
& \Rightarrow C_{t}^{-\sigma}=\lambda_{t} .
\end{aligned}
$$

Take the first order derivative with respect to $k_{t+1}$, 


$$
\begin{aligned}
& \frac{\partial \mathcal{L}}{\partial k_{t+1}}=0 . \\
\Rightarrow & \beta^{t} \lambda_{t}(-1)(1+n)+\beta^{t+1} \lambda_{t+1}\left[\left(1-\tau_{t+1} A+(1-\delta)=0\right.\right. \\
\Rightarrow & \lambda_{t}(1+n)=\beta \lambda_{(t+1)}\left[\left(1-\tau_{t+1}\right) A+(1-\delta)\right] .
\end{aligned}
$$

Now take the derivative with respect to $b_{t+1}$.

$$
\begin{aligned}
& \frac{\partial \mathcal{L}}{\partial \mathrm{b}_{\mathrm{t}+1}}=0 \\
& \Rightarrow \beta^{\mathrm{t}} \lambda_{\mathrm{t}}(-1)(1+\mathrm{n})\left(\frac{1}{\mathrm{R}_{\mathrm{t}}}\right)+\beta^{\mathrm{t}+1} \lambda_{\mathrm{t}+1}=0 \\
& \Rightarrow \lambda_{\mathrm{t}}(1+\mathrm{n})\left(\frac{1}{\mathrm{R}_{\mathrm{t}}}\right)=\beta \lambda_{\mathrm{t}+1} \\
& \Rightarrow \lambda_{\mathrm{t}}(1+\mathrm{n})=\beta \lambda_{\mathrm{t}+1} \mathrm{R}_{\mathrm{t}} .
\end{aligned}
$$

Now finally take the derivative with respect to $\lambda_{t}$.

$$
\begin{aligned}
& \frac{\partial \mathcal{L}}{\partial \lambda_{t}}=0 . \\
& \Rightarrow \lambda_{t}(1+n)=\beta \lambda_{(t+1)} R_{t} . \\
& C_{t}^{-\sigma}=\lambda_{t} .
\end{aligned}
$$

For the period $t+1$,

$$
\begin{aligned}
& C_{t+1}^{-\sigma}=\lambda_{t+1} . \\
& C_{t}^{-\sigma}(1+n)=\beta C_{t+1}^{-\sigma} R_{t} . \\
& \Rightarrow\left(\frac{C_{t}}{C_{t+1}}\right)^{-\sigma}=\frac{\beta R_{t}}{1+n} \\
& \Rightarrow\left(\frac{C_{t+1}}{C_{t}}\right)^{+\sigma}=\frac{\beta R_{t}}{1+\mathrm{n}} . \\
& \Rightarrow \frac{C_{t+1}}{C_{t}}=\left[\frac{\beta R_{t}}{1+n}\right]^{\frac{1}{\sigma}}
\end{aligned}
$$




\section{A.2. Consumption function evaluated from period 0 to $t$ times}

$$
\begin{aligned}
& C_{0}+(1+n) k_{1}+(1+n) \frac{b_{1}}{R_{0}}=\left(1-\tau_{0}\right) A k_{0}+(1-\delta) k_{0}+b_{0}+g_{0} \\
& \Rightarrow C_{0}+(1+n)\left[k_{1}+\frac{b_{1}}{R_{0}}\right]=\left[\left(1-\tau_{0}\right) A+(1-\delta)\right] k_{0}+b_{0}+g_{0} \\
& \Rightarrow R_{-1}\left[k_{0}+\frac{b_{0}}{R_{-1}}\right]=\left[c_{0}-g_{0}\right]+(1+n)\left[k_{1}+\frac{b_{1}}{R_{0}}\right]
\end{aligned}
$$

Now consider the consumption function [3] evaluated in period 1:

$$
\begin{aligned}
& C_{1}+(1+n)\left[k_{2}+\frac{b_{2}}{R_{1}}\right]=R_{0}\left[k_{1}+\frac{b_{1}}{R_{0}}\right]+g_{1} . \\
& \Rightarrow R_{0}\left[k_{1}+\frac{b_{1}}{R_{0}}\right]=\left[c_{1}-g_{1}\right]+(1+n)\left[k_{2}+\frac{b_{2}}{R_{1}}\right] \\
& \Rightarrow k_{1}+\frac{b_{1}}{R_{0}}=\left(\frac{1}{R_{0}}\right)\left[c_{1}-g_{1}\right]+(1+n)\left[k_{2}+\frac{b_{2}}{R_{1}}\right]\left(\frac{1}{R_{0}}\right) . \\
& \Rightarrow R_{-1}\left[k_{0}+\frac{b_{0}}{R_{-1}}\right]=\left[c_{0}-g_{0}\right]+(1+n)\left(\frac{1}{R_{0}}\right)\left[c_{1}-g_{1}\right]+(1+n)^{2}\left(\frac{1}{R_{0}}\right)\left[k_{2}+\frac{b_{2}}{R_{1}}\right]
\end{aligned}
$$

Now consider the consumption function [3] evaluated in period 2:

$$
\begin{aligned}
& C_{2}+(1+n)\left[k_{3}+\frac{b_{3}}{R_{2}}\right]=R_{1}\left[k_{2}+\frac{b_{2}}{R_{1}}\right]+g_{2} . \\
& \Rightarrow R_{1}\left[k_{2}+\frac{b_{2}}{R_{1}}\right]=\left[c_{2}-g_{2}\right]+(1+n)\left[k_{3}+\frac{b_{3}}{R_{2}}\right] . \\
& \Rightarrow k_{2}+\frac{b_{2}}{R_{1}}=\left(\frac{1}{R_{1}}\right)\left[c_{2}-g_{2}\right]+(1+n)\left[k_{3}+\frac{b_{3}}{R_{2}}\right]\left(\frac{1}{R_{1}}\right) . \\
& \Rightarrow R_{-1}\left[k_{0}+\frac{b_{0}}{R_{-1}}\right] \\
& =\left[c_{o}-g_{0}\right]+(1+n)\left(\frac{1}{R_{0}}\right)\left[c_{1}-g_{1}\right]+(1+n)^{2}\left(\frac{1}{R_{0}}\right)\left(\frac{1}{R_{1}}\right)\left[c_{2}-g_{2}\right] \\
& +(1+n)^{3}\left(\frac{1}{R_{0}}\right)\left(\frac{1}{R_{1}}\right)\left[k_{3}+\frac{b_{3}}{R_{2}}\right] .
\end{aligned}
$$


$\Rightarrow R_{1}\left[k_{0}+\frac{b_{0}}{R_{-1}}\right]=\sum_{s=0}^{2}(1+n)^{s}\left[\frac{c_{s}-g_{s}}{\pi_{s=0}^{1} R_{s}}\right]+(1+n)^{3}\left[\frac{\left\{k_{3}+\left(\frac{b_{3}}{R_{2}}\right)\right\}}{\pi_{s=0}^{1} R_{s}}\right]$.

Repeating forward substitution $\mathrm{t}$ times:

$R_{-1}\left[k_{0}+\left(\frac{b_{0}}{R_{-1}}\right)\right]=\sum_{s=o}^{t}(1+n)^{s}\left[\frac{C_{s}-g_{s}}{\pi_{s=0}^{t-1} R_{s}}\right]+(1+n)^{t+1}\left[\frac{\left\{k_{t+1}+\left(\frac{b_{t+1}}{R_{t}}\right)\right\}}{\pi_{s=0}^{t-1} R_{S}}\right]$.

Although any individual consumer is permitted to sell both capital and bonds short in any given period but no one is allowed to borrow more than they can ever pay back. This condition enters into the transversality condition,

$\lim _{t \rightarrow \infty}(1+n)^{t+1}\left[\frac{\left\{k_{t+1}+\left(\frac{b_{t+1}}{R_{t}}\right)\right\}}{\pi_{s=0}^{t-1} R_{s}}\right]=0$. 


\section{References}

Agell, J., \& Persson, M. (2001). On the analytics of the dynamic Laffer curve. Journal of Monetary Economics, 48, 397-414.

Dalamagas, B. (1998). Endogenous growth and the dynamic Laffer curve. Applied Economics, $30,63-75$.

Jones, L.E., R.E Manuelli, and P.E.Rossi, 1993, Optimal taxation in models of endogenous growth, Journal of Political Economy 101,458-517.

King, R.G. and S. Rebelo, 1990, Public policy and economic growth: Developing neoclassical implications, Journal of Political Economy 98, S126-S150.

Mankiw N.G., M. Weinzierl, D. Yagan, Optimal taxation in theory and practice, Journal of Economic Perspectives, 23 (2009), pp. 147-174

Novales, A., \& Ruiz, J. (2002). Dynamic Laffer curves. Journal of Economic Dynamics and Control, 27, 181-206.

P.N. Ireland., Supply side economics and endogenous growth, Journal of Monetary Economics, 33 (1994), 559-571. North Holland.

Solow, R. M., 1956, A contribution to the theory of economic growth, Quarterly Journal of Economics 70, 65-94.

Santacreu, Ana Maria. " Long-Run Economic Effects of Changes in the Age Dependency Ratio" Federal Reserve Bank of St. Louis On The Economy Blog, September

02,2016; https://www.stlouisfed.org/on-the-economy/2016/aug....

Strulik, H., \& Trimborn, T. (2012). Laffer strikes again: Dynamic scoring of capital taxes.

European Economic Review, 56, 1180-1199.

Trabandt, M., \& Uhlig, H. (2011). The Laffer curve revisited. Journal of Monetary Economics, 58, 305-327. 